\title{
Engineered Nanomaterials: The Challenges and Opportunities for Nanomedicines
}

This article was published in the following Dove Press journal:

International Journal of Nanomedicine

\author{
Fahad Albalawi (D) ${ }^{1,2, *}$ \\ Mohd Zobir Hussein (1D) ${ }^{2, *}$ \\ Sharida Fakurazi ${ }^{3,4}$ \\ Mas Jaffri Masarudin (D) 5 \\ 'Department of Medical Laboratory and \\ Blood Bank, King Fahad Specialist \\ Hospital-Tabuk, Tabuk, Saudi Arabia; \\ ${ }^{2}$ Materials Synthesis and Characterization \\ Laboratory, Institute of Advanced \\ Technology (ITMA), Universiti Putra \\ Malaysia, Serdang, Selangor, Malaysia; \\ ${ }^{3}$ Department of Human Anatomy, Faculty \\ of Medicine and Health Sciences, \\ Universiti Putra Malaysia, Serdang, \\ Selangor, Malaysia; ${ }^{4}$ Natural Medicine and \\ Product Research Laboratory Institute of \\ Bioscience, Serdang, Selangor, Malaysia; \\ ${ }^{5}$ Department of Cell and Molecular \\ Biology, Faculty of Biotechnology and \\ Biomolecular Sciences, Universiti Putra \\ Malaysia, Serdang, Selangor, Malaysia
}

*These authors contributed equally to this work

Correspondence: Mohd Zobir Hussein Email mzobir@upm.edu.my

\begin{abstract}
The emergence of nanotechnology as a key enabling technology over the past years has opened avenues for new and innovative applications in nanomedicine. From the business aspect, the nanomedicine market was estimated to worth USD 293.1 billion by 2022 with a perception of market growth to USD 350.8 billion in 2025. Despite these opportunities, the underlying challenges for the future of engineered nanomaterials (ENMs) in nanomedicine research became a significant obstacle in bringing ENMs into clinical stages. These challenges include the capability to design bias-free methods in evaluating ENMs' toxicity due to the lack of suitable detection and inconsistent characterization techniques. Therefore, in this literature review, the state-of-the-art of engineered nanomaterials in nanomedicine, their toxicology issues, the working framework in developing a toxicology benchmark and technical characterization techniques in determining the toxicity of ENMs from the reported literature are explored.
\end{abstract}

Keywords: engineered nanomaterials, nanomedicine, nanotoxicology, particle tracking analysis, asymmetric flow field-flow fractionation, Taylor dispersion analysis

\section{Introduction}

Nanomaterials have been reported to show promising potential in key industries, specifically in nanomedicine, pharmacology, and biomedical fields. ${ }^{1}$ Lucrative funding has been invested in nanotechnology research. ${ }^{2}$ By the year 2024, the global nanotechnology market is anticipated to exceed USD124billion, with more than $50 \%$ of the market falls in the Asia Pacific region. ${ }^{3,4}$ These opened avenues for innovative applications in medical fields, also known as nanomedicine. ${ }^{5}$ Nanomedicine can be defined as the use of nanomaterials for medical purposes in medical diagnostic, therapeutic techniques, disease control and prevention. ${ }^{6}$

Engineered nanomaterials (ENMs), with a size of $100 \mathrm{~nm}$ or less, are synthesized from numerous types of nanomaterials. ${ }^{7}$ ENMs offer great opportunities to nanomedicine and have been increasingly commercialized in several industries, as described in Table 1. According to the British Broadcasting Corporation (BBC) Research in 2014, nanomedicine represented $15 \%$ in the pharmaceutical market and was increased to $22 \%$ in $2019 .^{8}$ Based on the reported statistics, the nanomedicine business was estimated to worth USD293.1 billion dollars by 2022 with a perception of market growth to USD350.8 billion in $2025 .^{9,10}$ This ignites the great potential in the medical and pharmaceutical industries. For the application in nanomedicine, ENMs exhibit exceptional physicochemical properties in terms of 
Table I Essential Applications of ENMs ${ }^{172-176}$

\begin{tabular}{|l|l|l|}
\hline Categories & Applications & Ref. \\
\hline Medical diagnosis & Bioimaging & {$[1,178,179]$} \\
& In-vitro diagnosis & {$[180,181]$} \\
& Biosensing & {$[182,183]$} \\
\hline Therapeutic techniques & Drug delivery & {$[184-186]$} \\
& Gene therapy & {$[179,186,187]$} \\
\hline \multirow{2}{*}{ Disease control or applications } & Tissue engineering & {$[184,188]$} \\
& Vaccination & {$[185,188]$} \\
\hline
\end{tabular}

functionality, sensitivity, efficiency and specificity, which allows them to be used with better successes in the therapeutic and other biomedical applications. ${ }^{11}$

It has been reported that ENMs show various unique features that enhancing their use in various medical applications. ${ }^{12}$ For specific interactions between nanoparticles and cells, the adsorptive physio-chemical properties of the nanoparticles can be altered by selectively functionalizing the particle surfaces. ${ }^{13}$ In terms of combined immunotherapy treatment of cancerous tumors, nanoscaled photothermal treatment can be realized by photosensitizer molecules, where directional-specified irradiation can be achieved after injecting these molecules into the tumor region. ${ }^{14,15}$ Besides the abovementioned examples, other unique features of nanomaterials, including controllable nanocluster size, ${ }^{16}$ high surface dispersity, ${ }^{17}$ and tunable morphology ${ }^{18}$ enable ENMS in providing new opportunities and innovation for numerous applications in nanomedicine. ${ }^{19}$

For ENMs application in nanomedicine, Chen et al reported the application of platinum nanoclusters for selfbioimaging-guided cancer theranostics. By employing an in-situ, spontaneous biosynthesized approach, fluorescent platinum nanoclusters can be obtained in the biological environment. ${ }^{20}$ Zhu et al reported on a highly selective drug release using smart nanosized micelles. Using the hyaluronic acid-tocopherol succinate binds, a smart nanosized micelle demonstrated controlled drug release in the biosystem, suggesting an outstanding therapeutic effect against colon cancer. ${ }^{21}$ In addition, other applications such as bioimaging, photothermal treatment, tissue engineering and other biomedical applications have been demonstrated using ENMs. ${ }^{22,23}$

Despite the outstanding potential of ENMs in nanomedicine, several concerns exist in their applications. Due to the tunable physicochemical properties of ENMs, they induce the production of specific chemical environments for a pro-oxidant species within the cells. ${ }^{24}$ This initiates the disruption of cellular energy homeostasis, causing aggressive biological side effects such as an inflammatory reaction and eventual cell death. ${ }^{25,26}$ Thus, nanomaterials should be wisely designed in terms of their intrinsic physicochemical properties and surface chemistry to achieve specific biomedical applications. In this stage, the toxicological profile of ENMs and their toxicological mechanisms are under-explored. ${ }^{27,28}$

Nanotoxicology studies the inter-reactions between ENMs and biological surroundings. ${ }^{29,30}$ The scope of this field focuses mainly on the investigation of the correlations between ENMs toxicity and adversarial biological responses to their physicochemical properties and surface chemistry. ${ }^{11,31}$ This helps to determine the advantages of ENMs in terms of physicochemical characteristics for flexible designs of ENMs. ${ }^{29,32-36}$ The paradigm of nanotoxicology also involves ENMs toxicity, which is a challenging issue in realizing the full application of ENMs in nanomedicine. ${ }^{13,14}$ Therefore, comprehensive understandings of the interactions of ENMs, include the extra-/intracellular mechanisms on the cellular level is crucial. $^{37-39}$

In this review, we investigate the state-of-the-art challenges in determining the toxicity of ENMs, highlighting the reported strategies in characterizations and toxicity measurement and describing some of the emerging alternatives of their characterization methods. At the same time, we also explore the future standard characterization methods, which could provide the required knowledge to avoid potential risks associated with ENMs.

\section{ENMs in Nanomedicine}

Over the past decades, ENMs have been extensively used in nanomedicine. One of the significant applications is the specialized drug delivery in deploying liposomes to nanoshells and transdermal patches. These ENMs can be engineered at nanoscale to tune the delivery and releasing efficiency. At the same time, the development of biocompatible nanomaterial prosthetic implants, and the metalcontaining functionalized nanoparticles, have shown high localization, patient-specific functionalities in the bioimaging and treatment of various cancers. ${ }^{5}$ By integrating ENMs usage to AI technologies, ENMs can realize the development of internet-linked diagnostic devices (eg, "doctor-on-a-chip" diagnostic tools). At the same time, nanobionics can facilitate the incompatibility issues between 
medical devices or bionic prosthetics and the nervous system. The bionic prosthetics can replace the traditional invasive cranial sensing electrodes made of traditional cytotoxic metals with more biocompatible surface transistors. ${ }^{40}$

In this chapter, the usage of ENMs in nanomedicine will be discussed. The discussion includes a list of FDAapproved ENMs, and applications of ENMs in nanomedicine from various prospects.

\section{FDA-Approved ENMs for Nanomedicine Applications}

The field of nanomedicine is continuously growing, developing and optimizing to improve small molecules and drugs with key pharmacological properties like solubility, bioavailability and targeted delivery of the therapeutic agent to the diseased tissues. ${ }^{41,42}$ Over the past years, the food and drug agencies (FDA) in the US and EU have certified numerous nanomedicine-based drugs for cancer diagnostic and therapeutic purposes, and many others are currently evaluated to be released in the market. ${ }^{43}$

Among the approved drugs, about 250 drugs were produced based on the nanotechnology platform, either on the market or in clinical trials. ${ }^{44}$ Among the reported drugs, polymeric nanoparticles are commonly-used for nanomedicines due to their facile synthesis and wide applicability across all aspects of the field. The description of the trends in the development of nanomedicine is shown in Figure $1 .{ }^{45}$ From the list of FDA-approved nanomedicines, polymeric micelles occupy a significant fraction. Due to the self-assembled polymeric amphiphiles structures, polymeric micelles are ideal for the controlled delivery of hydrophobic drugs. ${ }^{45}$ The hydrophobic nature of the core can confine hydrophobic drugs, whereas the charged outer surface can dissolve hydrophilic drugs. At this stage, the only FDA-approved micelle is Estrasorb ${ }^{\mathrm{TM}}$, a conventional form of estradiol is used as a topical treatment for vasomotor symptoms of menopause. ${ }^{46}$ Table 2 shows the list of FDA-approved nanomedicine.

Apart from polymeric micelles, liposome has also been widely used among FDA-approved medicine. Liposomes are self-integrating structures with surrounding amphipathic domains. At the same time, the aqueous core accommodates instant chemical hybridization of various molecular species with distinct physico-chemical properties. Due to the unique combination of structural properties, liposomes are seemed to be the most readilyfabricated class of nanoparticles. ${ }^{48}$ The pioneering FDAapproved liposome nanoparticles include liposomal formulations of doxorubicin and Amphotericin B, which an antifungal medication used for serious fungal infections and leishmaniasis. ${ }^{49}$ One of the most recently-approved liposomal nanoparticles by the FDA is Onivyde ${ }^{\circledR}$ (liposomal irinotecan). Onivyde ${ }^{\circledR}$ is a topoisomerase I inhibitor used as a second-line treatment for metastatic pancreatic cancer, where prescribed patients were shown to have a $\sim 50 \%$ improvement in median survival duration as compared to conventional cancer drugs. ${ }^{51}$

Besides the abovementioned nanoparticles, nanocrystals also occupy a significant amount in the list of FDA-approved

\section{A FDA Approved Nanomedicines}

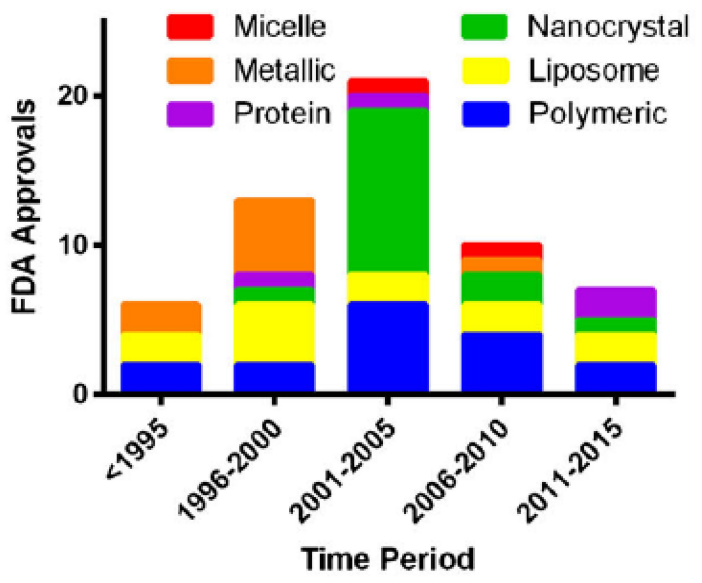

B

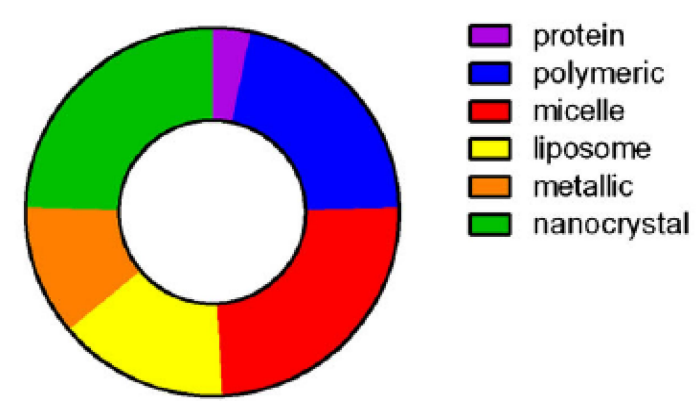

Figure I Trends in the development of nanomedicines. (A) FDA-approved nanomedicines stratified by category; (B) FDA-approved nanomedicines stratified by category overall.

Notes: Reprinted by permission from Springer Nature Customer Service Centre GmbH: Springer Nature; Nature Nanotechnology; Bobo D, Robinson KJ, Islam J, Thurecht KJ, Corrie SR. Nanoparticle-based medicines: a review of FDA-approved materials and clinical trials to date. Pharm Res. 2016;33:2373-2387; Copyright 2016. ${ }^{45}$ 
Table 2 List of FDA-Approved Nanomedicine

\begin{tabular}{|c|c|c|c|}
\hline Name & Particle type/drug & Approved application/indication & $\begin{array}{l}\text { year of } \\
\text { approval } \\
\text { (FDA) }\end{array}$ \\
\hline $\begin{array}{l}\text { VYXEOS CPX-35I (Jazz } \\
\text { Pharmaceuticals) }\end{array}$ & $\begin{array}{l}\text { Liposomal formulation of cytarabine: } \\
\text { daunorubicin ( } 5 \text { : IM ratio) }\end{array}$ & Acute myeloid leukemia & 2017 \\
\hline $\begin{array}{l}\text { ONPATTRO Patisiran ALN- } \\
\text { TTR02 (Alnylam } \\
\text { Pharmaceuticals }\end{array}$ & $\begin{array}{l}\text { Lipid nanoparticle RNAi for } \\
\text { theknockdown of disease-causingTTR } \\
\text { protein }\end{array}$ & Transthyretin (TTR)-mediated amyloidosis & 2018 \\
\hline Doxil Caelyx (Janssen) & Liposomal doxorubicin (PEGylated) & $\begin{array}{l}\text { Ovarian cancer (secondary to platinum based therapies) HIV-associated } \\
\text { Kaposi's sarcoma (secondary to chemotherapy) Multiple myeloma } \\
\text { (secondary) }\end{array}$ & 1995 \\
\hline DaunoXome (Galen) & $\begin{array}{l}\text { Liposomal daunorubicin } \\
\text { (nonPEGylated) }\end{array}$ & HIV-associated Kaposi's sarcoma (primary) & 1996 \\
\hline Abraxane (Celgene) & Albumin-particle bound paclitaxe & $\begin{array}{l}\text { Advanced non-small cell lung cancer (surgery or radiation is not an option) } \\
\text { Metastatic breast cancer (secondary) Metastatic pancreatic cancer (primary }\end{array}$ & 2005 \\
\hline Marqibo (Spectrum) & $\begin{array}{l}\text { Liposomal vincristine (non- } \\
\text { PEGylated) }\end{array}$ & Philadelphia chromosomenegative acute lymphoblastic leukemia (tertiary) & 2012 \\
\hline Onivyde MM-398 (Merrimack) & Liposomal irinotecan (PEGylated) & Metastatic pancreatic cancer (secondary) & 2015 \\
\hline $\begin{array}{l}\text { CosmoFer INFeD Ferrisat } \\
\text { (Pharmacosmos }\end{array}$ & Iron dextran colloid & Iron deficient anemia & 1992 \\
\hline $\begin{array}{l}\text { DexFerrum DexIron } \\
\text { (American Regent) }\end{array}$ & Iron dextran colloid & Iron deficient anemia & 1996 \\
\hline Ferrlecit (Sanofi) & Iron gluconate colloid & $\begin{array}{l}\text { Iron replacement for anemia treatment in patients with chronic kidney } \\
\text { disease }\end{array}$ & 1999 \\
\hline Venofer (American Regent) & Iron sucrose colloid & $\begin{array}{l}\text { Iron replacement for anemia treatment in patients with chronic kidney } \\
\text { disease }\end{array}$ & 2000 \\
\hline $\begin{array}{l}\text { Feraheme (AMAG) Rienso } \\
\text { (Takeda) Ferumoxytol }\end{array}$ & $\begin{array}{l}\text { Iron polyglucose sorbitol } \\
\text { carboxymethylether colloid }\end{array}$ & Iron deficiency in patients with chronic kidney disease & 2009 \\
\hline Injectafer Ferinject (Vifor) & Iron carboxymaltose colloid & Iron deficient anemia & 2013 \\
\hline $\begin{array}{l}\text { Definity (Lantheus Medical } \\
\text { Imaging) }\end{array}$ & Perflutren lipid microspheres & Ultrasound contrast agent & 2001 \\
\hline Feridex I.V. (AMAG) Endorem & Iron dextran colloid & Imaging of liver lesions & 1996 \\
\hline Optison(GE Healthcare) & $\begin{array}{l}\text { Human serum albumin stabilized } \\
\text { perflutren microspheres }\end{array}$ & Ultrasound contrast agent & 1997 \\
\hline Diprivan & Liposomal propofol & Induction and maintenance of sedation or anesthesia & 1989 \\
\hline AmBisome (Gilead Sciences) & Liposomal amphotericin B & $\begin{array}{l}\text { Cryptococcal meningitis in HIVinfected patients Aspergillus, Candida and/or } \\
\text { Cryptococcus species infections (secondary) Visceral leishmaniasis parasite } \\
\text { in immunocompromised patients }\end{array}$ & 1997 \\
\hline Visudyne (Bausch and Lomb) & Liposomal verteporfin & $\begin{array}{l}\text { Treatment of subfoveal choroidal neovascularization from age-related } \\
\text { macular degeneration, pathologic, or ocular histoplasmosis }\end{array}$ & 2000 \\
\hline
\end{tabular}

Notes: Reproduced from Anselmo AC, Mitragotri S. Nanoparticles in the clinic: An update. Bioeng Transl Med. 2019;4(3):el0I4347. 
substances in nanomedicine. Fundamentally, crystalline nanomedicines themselves are composed of $100 \%$ drug compound. Attributing to the nano-scaled structures, the high dissolution surface area of nanocrystals enhances the dissolution rate and saturation solubility. Most importantly, the miniaturized particles of nanocrystals increase the dissolution, resulting in improved driving forces for diffusion-based mass transfer through biological structures. ${ }^{51}$ The first nanocrystal element approved by FDA is Rapamune (the year 2000). The active sirolimus component in Rapamune can be used to prevent organ rejection upon transplantation. After this approval, there have been several other approved nanocrystalline drug formulations, where the last of which was approved in $2009 .^{52}$

\section{Engineered Nanomaterials for Nanomedicine Applications}

In compiling various approaches in the use of ENMs in cancer treatment, four directions in utilizing ENMs in nanomedicine in refining their cancer-treating performance were proposed, as shown in Figure $2 .{ }^{53}$ These four directions include patient stratification, drug selection, immunomodulation and combination therapies. For patient stratification, nanomedicine such as liposomal doxorubicin, Myocet $^{\mathrm{TM}}$, and DaunoXome ${ }^{\mathrm{TM}}$, have been used in exploiting the enhanced permeability and retention (EPR) effect in the stratification of cancer patients. $^{54}$

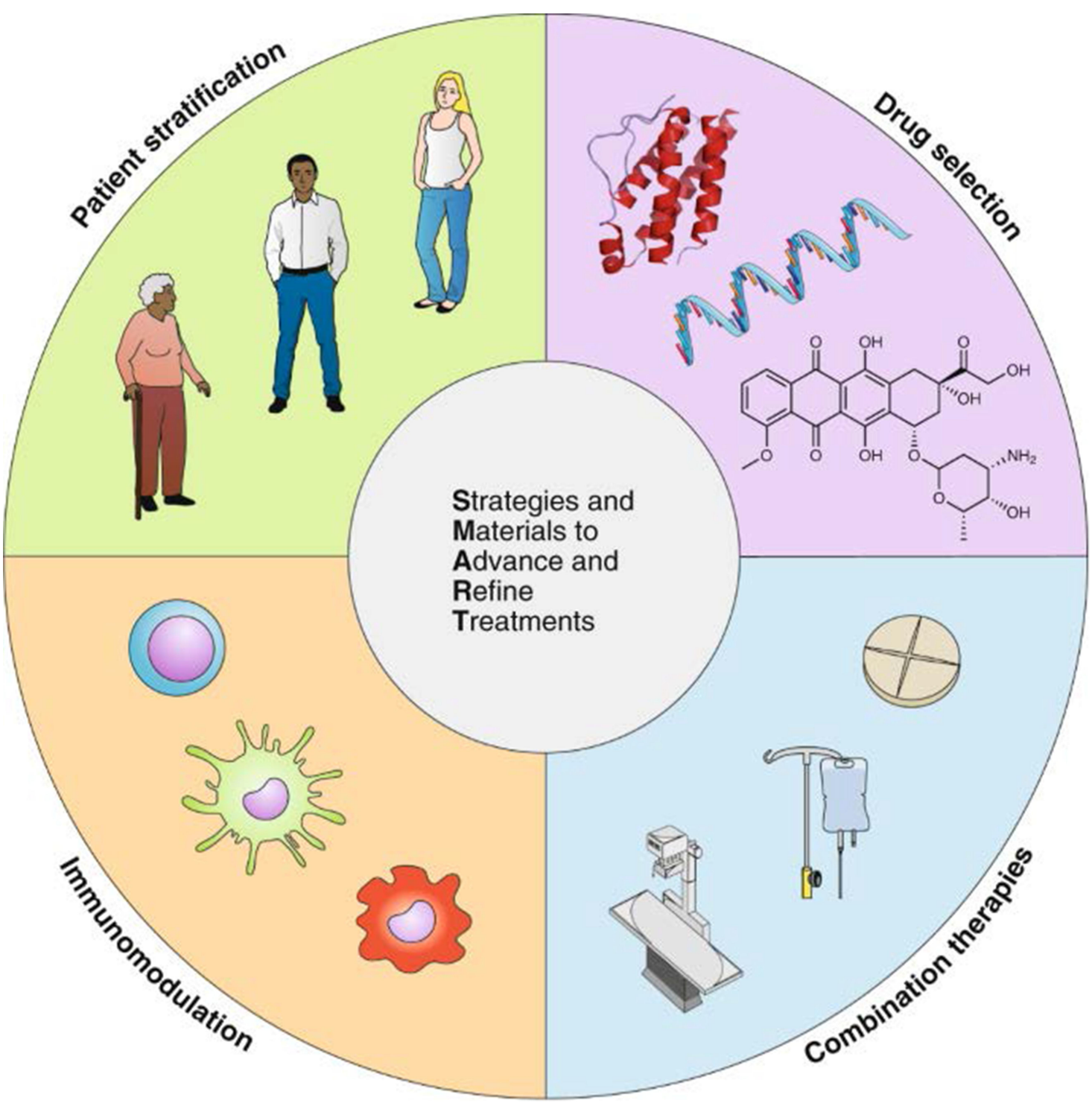

Figure 2 Four directions in utilizing ENMs in nanomedicine in refining their cancer-treating performance.

Notes: Reprinted by permission from Springer Nature Customer Service Centre GmbH: Springer Nature; Nature Nanotechnology; van der Meel R, Sulheim E, Shi Y, et al. Smart cancer nanomedicine. Nat Nanotechnol. 2019;14:1007-1017; Copyright 2019.53 
Combining the enhanced biomarking strategies with nanocarriers and artificial intelligence (AI) for precision oncology, an integrated nanomedicine-AI strategy can be developed in identifying and stratifying early cancer patients. ${ }^{55}$ In nanomedicine, optimizing the treatment outcomes relies on 2 stages of development. Firstly, the drug and dose space to optimize their efficiency and safety. After that, the variable synergy takes place. The dosedependent and patient-specific nature of synergy require dynamic dosage to optimize the treatment. In conjunction with the drug and dose space, AI-enabled approaches take various factors into considerations, such as drug targeting, ratio-metric delivery, and other properties. In the case of modulated treatment, dynamically modulating treatment requires an even higher degree of actionability in the clinic. This requirement represents an opportunity for the field of artificial intelligence (AI). ${ }^{56}$

In drug selection, nanocarrier technologies can significantly assist in enhancing the payload of DNA- and RNAbased drugs. For instance, the application of ENMs serves as a fundamental platform in assisting the development of other genome-induced nanomedicines, such as RNA-based vaccines for treating infections and selected cancers. The RNA encoding engineered in the vaccines can be utilized as a biological ground for protein production upon transportation to hepatocytes cells in the liver. ${ }^{57}$

Besides drug selection, the delivery of active ingredients towards tumor regions is an important aspect of cancer treatment. One of the proposed strategies is to employ a combined therapy, combining nanomedicine with a systematically administered drug. The combined therapies can help overcome barriers for tumor-targeted drug delivery. Various biological barriers including the dense extracellular matrix (ECM), the high interstitial fluid pressure (IFP) and the high metabolism in tumors exhibit significant barriers in targeted drug delivery, by utilizing combined therapy, such as integrated prescribed drugs with the angiotensin II receptor inhibitor losartan, the ECM and IFP contents in tumors can be reduced. As a result, it increases the nanomedicine's clinical efficacy and performance. ${ }^{58}$

Besides cancer detection, diagnosis, and treatment, nanomedicines have been used in the prevention efforts by enhancing the human body's immunity against cancer. For instance, ENMs used in chemotherapy, doxorubicin and oxaliplatin-induced counter-tumor immunity by triggering immunogenic cell death (ICD), promoting checkpoint blockade effects in immunotherapeutics. A simple explanation of better immunotherapy outcomes by ICDinducing nanomedicines can be described as the reduction of drug exposure by ICD-inducing nanomedicines resulting in less systemic immunodepression. ${ }^{59}$ Thus, it promotes the conversion of tryptophan to kynurenine, and induce immunosuppression in the human body.

Apart from the field of cancer treatment, ENMs are widely used in ocular drug delivery. As the eye is a sensitively accessible organ, it requires delicate handling in treatment, drug selection, and drug delivery. Attributing to their extremely high area to volume ratio, ENMs often have distinctive physicochemical properties as compared to their bulkier counterparts. ${ }^{60}$ Figure 3 shows the usage of nanomaterials as therapeutic agents for eye treatment. Various ENMs have been reported for drug delivery and treatment in ocular specialists, specifying corresponding eye-associated diseases. For example, Eleraky et al reported that surfactants are mixed in ENM composite to further disperse the nanoclusters, reducing the size of both ocular and drug emulsions. Despite the advantages of ENMs in ocular treatment, ionic surfactants are toxic generally toxic. The concentration of the surfactant shall be meticulously tuned as higher concentrations because it may cause irritation and corneal damage. Other solutions for toxicity in ionic surfactants include the usage of nonionic surfactants like poloxamers, polysorbates, polyethylene glycol, and tyloxapol. ${ }^{61}$

In the context of drug delivery, the efficiency of drug delivery is crucial especially in the field of cancer treatment. Various types of nanoparticles are used in drug delivery for cancer treatment. For instance, Cisplatin, an effective drug against breast, ovarian, head-neck, bladder and testicular tumors that can achieve efficient drug loading was measured as $\approx 100 \%$ with long blood circulating time of up to $15.53 \mathrm{~h}$. Besides, Oxaliplatin, an effective drug to treat colon cancer, shows drug loading efficiency of $75.69 \% .{ }^{62}$ For platinum-based nanoparticles in liposomal formulations, co-delivery of oxaliplatin and irinotecan by liposomal formulations is more efficient than synchronous and sequential administration of these drugs. ${ }^{63}$ In the context of hybrid nanomaterials for anticancer drug delivery, Wang et al reported Rational Design of DNA Framework-Based Hybrid Nanomaterials. The designed framework presents significant advances in drug delivery carriers such as precisely controlled topology, superb fluorescence property, high stability under physiological conditions, rapid internalization, as well as high biocompatibility. ${ }^{64}$ 


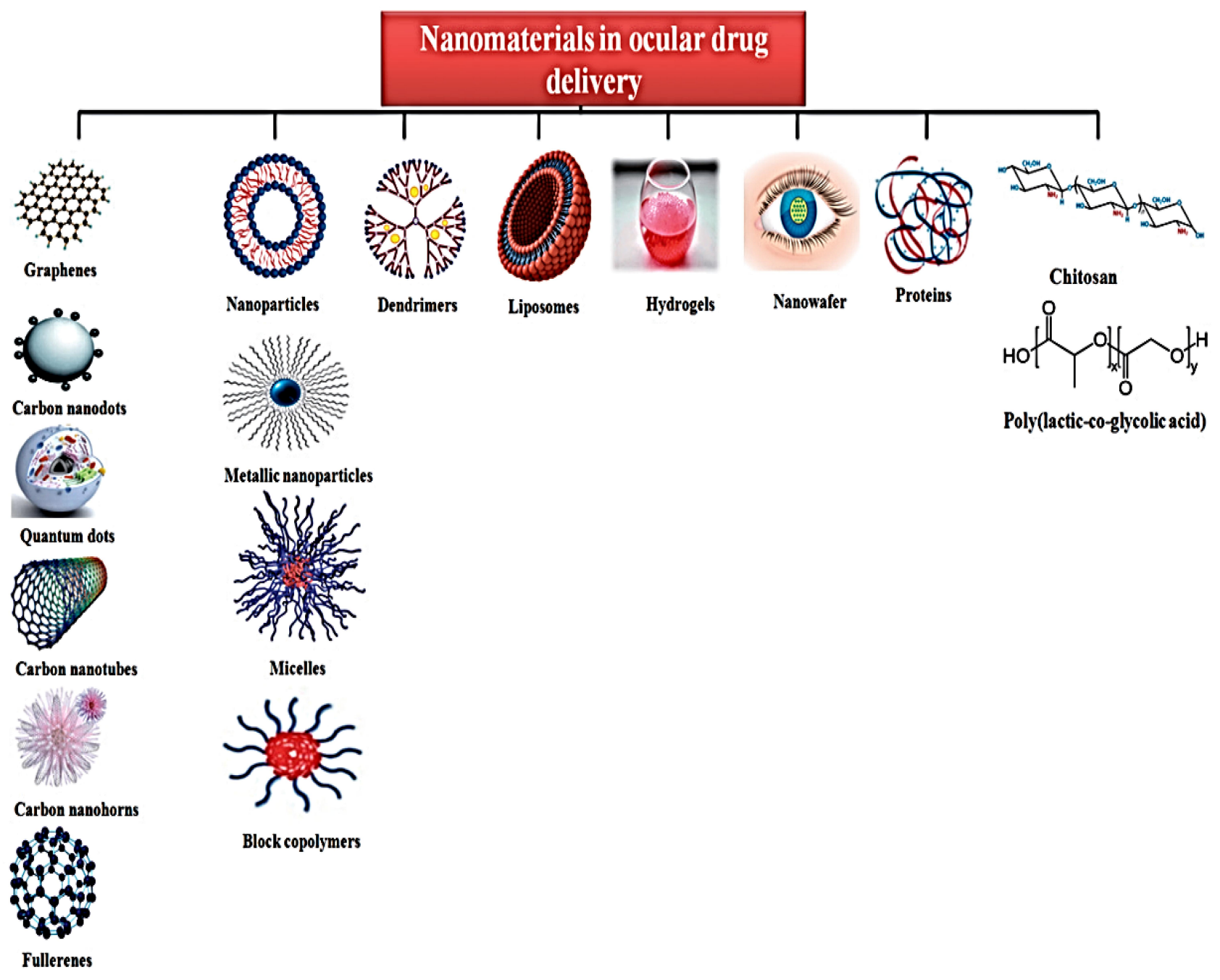

Figure 3 Nanomaterials used as therapeutic agents in nanomedicines, particularly ocular.

Notes: Mehra NK, Cai D, Kuo L, Hein T, Palakurthi S. Safety and toxicity of nanomaterials for ocular drug delivery applications. Nanotoxicology. 20I6; 10:836-860, reprinted by permission of the publisher (Taylor \& Francis Ltd, http://www.tandfonline.com). ${ }^{60}$

Besides the abovementioned directions, ENMs have also been used in antimicrobial applications, including antifungal, antibacterial and antiviral activities. Various researches reported the usage of ENMs as the remedy of infectious disease, for instance, $\mathrm{Fe}, \mathrm{Ag}, \mathrm{Cu}, \mathrm{TiO}_{2}$ and ZnONPs have been illustrated significant antibacterial activities against drug-resistant bacteria. The main antibacterial mechanism of these ENMs is primarily ion, which causes free radical stress in bacteria. ${ }^{65}$ In the case of Fe-based ENMs, Alavi et al demonstrate the antispreading ability of $\mathrm{Fe}_{3} \mathrm{O}_{4}$ nanoparticles towards multidrug resistance bacteria. In the reported study, $\mathrm{Fe}_{3} \mathrm{O}_{4}$ nanoparticles are attempted to investigate its antibacterial abilities on E. coli ATCC 25922, S. marcescens ATCC13880 and $S$. aureus ATCC 43300. From the reported study, S. aureus ATCC 43300 colony has been successfully suppressed with increasing about of $\mathrm{Fe}_{3} \mathrm{O}_{4}$ nanoparticles. ${ }^{65}$ Besides, Fe-based nanoparticles, Agbased particles has been paired with various biocompounds to form antibacterial nanoformulations. From the reported study, the bioactivity of Ag-based nanoformulation, including AgNP-chitosan, AgNP-cellulose, AgNPsodium alginate, and AgNP-chitosan-cellulose, may be influenced by many factors such as types of nanoformulation (films, foams, and hydrogels) and concentration or volume ratio of each ingredient. ${ }^{66}$ The possible applications from antibacterial properties of ENMs are not only limited to nanomedicine but also include food packaging, water disinfection, antimicrobial coatings, etc. ${ }^{67}$ Besides metallic-based ENMs, carbon-based ENMs, such as 
carbon nanotubes (CNTs) have been reported to show antibacterial activities. The open-ended structures of CNTs may encapsulate the antibacterial agent, which shows significant bactericidal effects. ${ }^{68}$

From the abovementioned discussion, it can be deduced that ENMs possess promising potential in the field of nanomedicine, including cancer treatment and ocular treatment. In terms of cancer treatment, ENMs have reported showing outstanding performances in patient stratification, drug selection, immunomodulation, and combination therapies. For ocular treatment, the adoption of various nanomaterials has been reported in various aspects of ocular treatment. However, the toxicity nature of most ENMs results in a significant obstacle against its realization in modern nanomedicine. Thus, various efforts shall be exerted to overcome this nanotoxicology issues in nanomedicine.

\section{Nanoparticles Affecting the Health}

The enormous success of nanotechnology in improving biomedical applications and innovations to overcome many of the health challenging issues leads to overlooking the toxicological aspect of ENMs. ${ }^{24,27,31,69,70}$ However, the recent concern on the toxicity and the behavior of ENMs among regulatory agencies has been growing, as implied by many studies reported in the nanomedicine community. However, the toxicological studies of ENMs are still under-explored in some aspects, specifically on the health complications of ENMs. Several health complications such as inhalation toxicity, cardiovascular, hepatotoxicity, neurodegenerative, and carcinogenicity of ENMs positioned it as a health threat in nanomedicine applications. $^{23-30}$

One of the challenges in resolving toxicity in ENMs is the difficulties to standardize and implement the method that reflects the real toxicity of organs and the exposure root in which the ENMs entered the body. ${ }^{24,25,28}$ The exposure roots include lung, skin, and mucous membranes, endothelium and blood cell components in addition to different organ toxicity, such as spleen, liver, nervous system, heart, and kidney. ${ }^{71,72}$ Once ENMs have entered the body as drug delivery or diagnostic tools, they induce physicochemical interactions with the immunology mechanisms in blood, muscle tissue, liver, spleen, and kidney. ${ }^{73,74}$ For inhaled ENMs, where immune cells can uptake and translocate them across epithelial and endothelial cells to the blood circulation system spreading to key organs, including the cardiovascular system, bone marrow, lymph nodes, and spleen. ${ }^{71,75-78}$ The translocation of inhaled ENMs causes them to retain around the respiratory tract regions through diffusional mechanisms, resulting in further medical complications. Besides, ENMs have also been detected on the CNS. $^{79,80}$ Adsorption of ENMs through the skin seems to be distributed through the lymphatic system. ${ }^{75,76,81}$ Orally administrated ENMs are mainly digested in the gastrointestinal system which is an acidic environment. The remaining survived ENMs from gastric juice may pass to the intestine and reach the bloodstream if not absorbed in hepatic portal circulation and eliminated by the liver. ${ }^{82,83}$

Figure 4 shows numerous exposure pathways and administration roots of the human body towards ENMs with their corresponding effects and linked diseases. The common cytotoxicity mechanisms of ENMs include inflammation, autophagy dysfunction, oxidative stress, cell membrane damage, immune system response, genotoxicity, alteration in cell structural or cell organelle morphology, cell cycle arrest, etc. ${ }^{25,70-72,75,76,82,84-86,87}$ The common effects and their mechanisms are further described in Table 3.

Besides the impact of ENMs' nanotoxicity on the human body, it is important to understand the molecular mechanism in the toxicity of ENMs. ${ }^{88}$ One of the prominent mechanisms is oxidative stress induced by ENMs. ${ }^{89}$ Oxidative stress is indicated by a rise in ROS level, which is primarily attributed to an imbalance between ROS production and antioxidant defense. Reactive oxygen species (ROS) are chemically reactive species (eg hydroxyl $(\cdot \mathrm{OH})$, superoxide $\left(\mathrm{O}^{2 \cdot-}\right)$, hypochlorous acid $(\mathrm{HOCl})$, singlet oxygen $\left({ }^{1} \mathrm{O}_{2}\right)$, and ozone $\left.\left(\mathrm{O}_{3}\right)\right)$. Fundamentally, ROS are biobased byproducts of oxidation metabolism in human tissues, including the cell membrane, cytoplasm, mitochondria, and endoplasmic reticulum (ER). ${ }^{90}$

Under normal conditions, the body possesses a low value of ROS, where only a small amount of reactive oxygen is present in the body. A small amount of ROS is needed for various functionalities in the body. For instance, in the kidney, the main role of ROS is to regulate the resorption of solutes and water. This is critical for maintaining electrolyte homeostasis and extracellular fluid volume. However, when the level of ROS increases to an undesired level, it can destroy the functionalities of the kidney. ${ }^{91}$ Studies have demonstrated that various types of ENMs, eg, gold, silver, and copper, were able to induce high ROS production. Besides kidney damage, several in vitro studies have shown that Ag-based ENMs may trigger ROS production by mediating mitochondrial dysfunction, leading to DNA damage. In the HK2 cell line, Ag NPs can induce ROS-mediated DNA damage and 


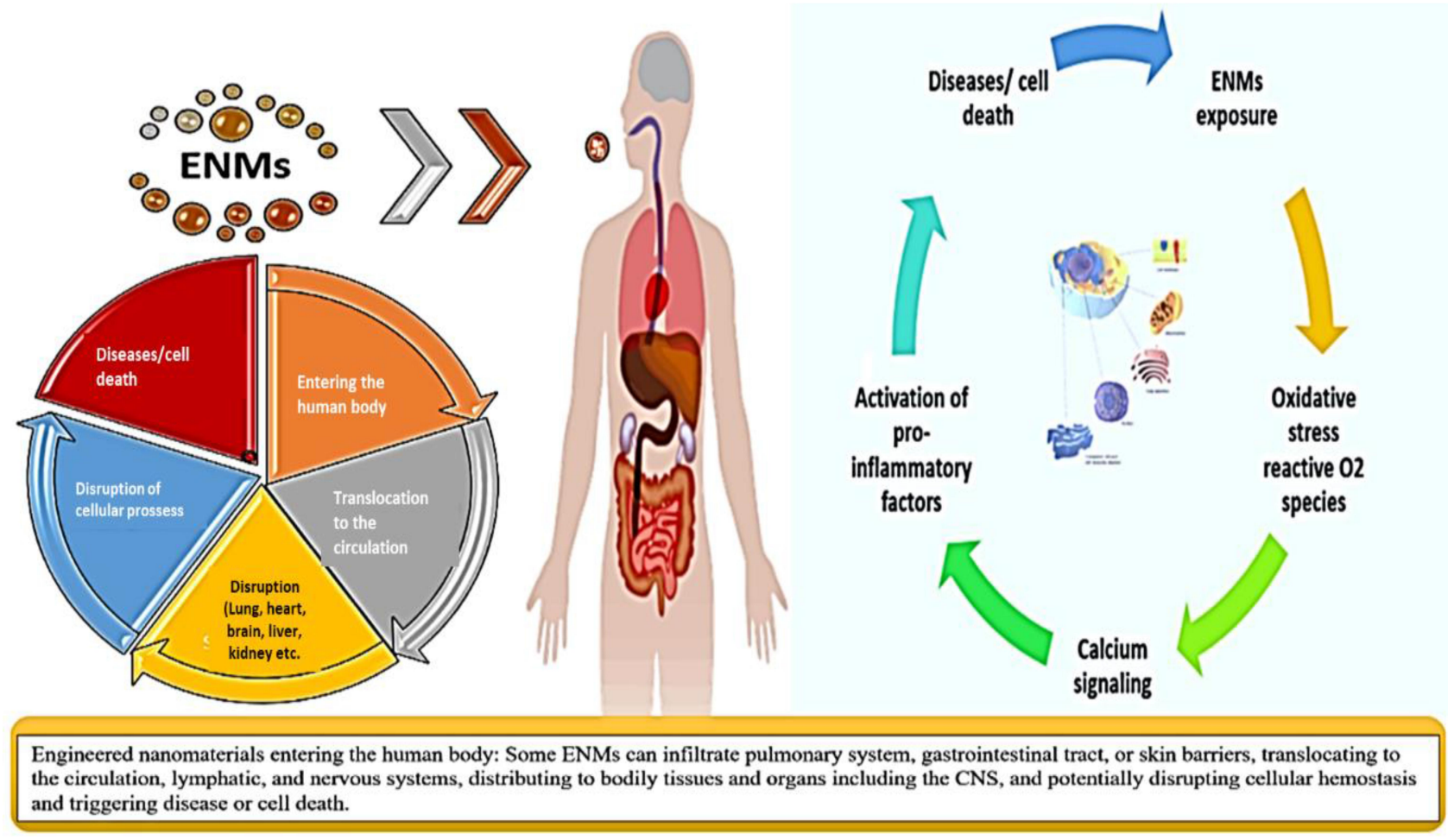

Figure 4 The fate of ENMs, their effects and cycle in human body.

subsequent $\mathrm{G} 2 / \mathrm{M}$ cell cycle arrest in human renal epithelial cells. ${ }^{92}$

Due to the toxicity nature of ENMs, it possesses a significant challenge in realizing ENMs in the nanomedicine field. To utilize the various advantages of ENMs in nanomedicine, the toxicity issue shall be evaluated and addressed. The details of the challenges and proposed solutions in resolving toxicities in ENMs shall be discussed in the next sections.

\section{The Challenges in Nanotoxicology}

The toxicity evaluation of ENMs in nanomedicine research possesses a challenge, where an objective strategy in determining the toxicity of individual ENMs is crucial. ${ }^{93-95}$ The fast development and commercialization of ENMs and the lack of suitable detection and characterization techniques exacerbated concerns over the potential risk of using ENMs. ${ }^{44,75,81}$ These need further clarifications to develop reproducible, adequate and validated methods for the detection and characterization of ENMs for toxicological studies to develop safe nano-based systems for clinical practices. ${ }^{42,44}$

In this stage, both in vivo and in vitro are established methods in determining ENMs' toxicity. Among the in vitro methods, inflammatory biomarkers and lactate dehydrogenase (LDH) assay is used to assess inflammatory response and cell integrity, respectively. However, due to their highly tunable properties of ENMs, the physicochemical properties of ENMs are sensitive, and relatively unstable compared to their counterpart bulk materials. Thus, its usage in assessing inflammatory response and cell integrity is relatively unreliable. ${ }^{95-97}$

As compared to in vitro method, in vivo model is the most acceptable testing system for regulatory agencies. This can be attributed to various advantages in in vivo model, including fast results, simple process, etc. However, the disadvantages of in vivo model include limitations in predicting human biological responses. Apart from the low throughput, the costs, and the ethical issues of in vitro and in vivo methods, they have given conflicting and inconsistent results in different laboratory settings. For usage of in vitro and in vivo methods in determining the toxicity of ENMs, ${ }^{76,93,94,96}$ these methods yield inconsistent ENMs toxicity results due to various factors. These include the nanoscale size versus large surface area, the high catalytic activity, and the unique optical properties. ${ }^{99-100}$

In addition to the agglomeration effects and the potential interference between ENMs and the currently available assay kits, all these have raised the need to adopt new 
Table 3 The Common Effects of ENMs and Their Mechanisms

\begin{tabular}{|c|c|c|c|}
\hline Type of Effect & Description & Mechanism & Ref. \\
\hline $\begin{array}{l}\text { Biodistribution- } \\
\text { related toxicity }\end{array}$ & $\begin{array}{l}\text { The behavior of an ENM in the physiological } \\
\text { surrounding will be determined by its dispersion in } \\
\text { various organs; heart, lungs, kidney, spleen, liver, brain, } \\
\text { testis and thymus, and by physicochemical properties } \\
\text { such as hydrophobicity, dissolution, and aggregation } \\
\text { state. Also, cell uptake and route of administration. }\end{array}$ & $\begin{array}{l}\text { Dissolution can result in a redox reaction, altering } \\
\text { the chemical reactivity of the ENM. } \\
\text { Adsorption of matrix components, the } \\
\text { agglomeration or sedimentation of the ENM can } \\
\text { significantly impact the delivery of the material and } \\
\text { its bioavailability }\end{array}$ & {$[71,78,79]$} \\
\hline $\begin{array}{l}\text { Reactive } \\
\text { oxygen species }\end{array}$ & $\begin{array}{l}\text { During the mitochondrial electron transport of } \\
\text { aerobic respiration or oxidoreductase enzymes and } \\
\text { metal-catalyzed oxidation, reactive molecules and } \\
\text { free radicals are emitted as by-products. These by- } \\
\text { products can be susceptible to causing a series of } \\
\text { catastrophic occurrences in the body. }\end{array}$ & $\begin{array}{l}\text { Superoxide anion, hydrogen peroxide and nitric } \\
\text { oxide }\end{array}$ & {$[31,78,85]$} \\
\hline Inflammation & $\begin{array}{l}\text { A major process where the body repairs damaged } \\
\text { tissue and protect its organs from outside invaders. } \\
\text { Acute inflammation is a typical response to an } \\
\text { incoming threat to eradicates foreign bodies, } \\
\text { damaged tissue, and stopping additional injury }\end{array}$ & $\begin{array}{l}\text { Macrophages present in the tissue acts as the } \\
\text { tissue's primary immune response, releasing } \\
\text { numerous cytokines and immune factors. Upon } \\
\text { interaction of macrophage with ENM, macrophages } \\
\text { differentiated to pro-inflammatory or anti- } \\
\text { inflammatory phenotypes depending on the ENM } \\
\text { nature }\end{array}$ & {$[75,76,83-85,190]$} \\
\hline $\begin{array}{l}\text { Cell membrane } \\
\text { damage }\end{array}$ & $\begin{array}{l}\text { The cell membrane separates and protects the } \\
\text { inner organelle of cells from the outside } \\
\text { environment. ENMs can pass cell membrane by } \\
\text { endocytosis or thru penetration. This may provoke } \\
\text { permanent cell damage and toxicity depends on } \\
\text { ENMs concentration and properties. }\end{array}$ & $\begin{array}{l}\text { Cell membrane disruptions and cell death typically } \\
\text { depending on various ENMs physiochemical } \\
\text { properties, such as size, surface charge, or } \\
\text { hydrophilicity. Adsorption of ENMs on cell } \\
\text { membranes may lead to blocking cellular ducts, } \\
\text { causing changes to membrane structures, or inhibiting } \\
\text { metabolism or ion intake causing cell death }\end{array}$ & {$[93,122]$} \\
\hline Genotoxicity & $\begin{array}{l}\text { Describes the damage of the genetic information } \\
\text { within a cell as a result of oxidation of critical cell } \\
\text { biomolecules lead to chromosomal aberrations, } \\
\text { gene mutations, apoptosis and carcinogenesis }\end{array}$ & $\begin{array}{l}\text { Alterations of redox equilibrium in the cell among } \\
\text { produced reactive oxygen species and antioxidant } \\
\text { leading to DNA damage. }\end{array}$ & {$[71,84,85,191,192]$} \\
\hline
\end{tabular}

alternative methods as a primary goal in nanotoxicology to identify the ENMs' potential health hazard to the environment and humans. ${ }^{101-105}$ Progress in the growth of nanotechnology and its translation to clinical practices requires comprehensive characterization of ENMs and detecting their toxicity based on feasible and cost-effective approaches include considering those characteristics as safe-by-design approaches. ${ }^{70,75,93,100}$ In addition to a suitable detection method to assess their potential toxicity, effective standardized regulatory guidelines are needed. ${ }^{42,44,75}$

\section{Nanotoxicology in Biodegradable Materials}

Due to the possible toxicity in ENM substances, there have been numerous research efforts in exploring low-toxicity alternatives for nanomedicine applications. Recently, much attention has been shifted to the research and development of biodegradable organic nanomaterials. ${ }^{105,106}$ These biodegradable nanomaterials can be degraded in the human body, resulting in chemical products that are cell building blocks, eg sugars, amino acids, and fatty acids. ${ }^{107}$ Due to the usage of biodegradable materials in nanomedicine, the toxicity of nanomaterials has been largely reduced. In most cases, these biodegradable nanomaterials are generally presumed to be nontoxic, despite possible toxic payload resulted from the treatments which are unavoidable. ${ }^{108}$ Despite the common practice in assuming biodegradable nanomaterials as non-toxic, one needs to take note that not all biodegradable nanomaterials are deemed safe, specifically for nanomedicine applications. Despite biodegradability properties, some 
nanoparticles may still have negative impacts on human bodies. For instance, attributing to their physiochemical properties, eg particle size, ionic polarity, insolubility, usage of specific biodegradable materials will cause undesired issues in the blood coagulation system. ${ }^{108}$ For example, $\mathrm{Su}$ et al reported that poly-alkyl-cyanoacrylate (PAC) can be degraded in the human system by esterases. However, the degradation rate produces toxic components, which are undesirable for nanomedicine applications. ${ }^{109}$ To control the release of toxic substances during biodegradation, various factors need to be considered, eg choice of nanomaterials, size, shape, surface polarity of the nanoparticles. ${ }^{110}$ In terms of material choices, Kim et al reported that the encapsulation efficiency of Poly- $\varepsilon$ Caprolactone (PCL) for taxol (anti-cancer drug) is $\sim 20 \%$. This encapsulation is much lower compared to its Poly Lactic-Co-Glycolic Acid (PLGA) counterparts with $\sim 100 \%$ encapsulation efficiency. However, due to the difference in chemical properties, PCL nanoparticles have better therapeutic efficiency and bio-stability as compared to PLGA substrates. ${ }^{111}$ Nevertheless, due to the relatively brief history of nanomedicine, the long-term effect of toxic payloads in biodegradation nanomaterials is still understudied. In conjunction with the toxicity concerns of nanomaterials in nanomedicine in general, the toxicity assessment and qualification standards in nanomedicine are called for.

\section{Toxicity Assessment and Qualification Standards in Nanomedicine \\ Approaches to Toxicity Assessment}

The dose-response relationship is the classical approach to evaluate toxicity, in which the steepest slope or setting a cut off is used for comparison. ${ }^{112,113}$ It is the most fundamental concept of toxicology, many decisions depend on the integrity of this relationship, serving as an important guideline for many regulatory, health and economic assessments. ${ }^{113}$ Though, many factors affecting the integrity of the dose-response relationship, including changes in the pharmacokinetics of the chemicals which are a common root for altered dose-response relationships. ${ }^{84,112}$ The pharmacokinetics of ENMs are significantly influenced by their physicochemical properties, which lead to significant unpredictability in absorption, clearance, and distribution. ${ }^{70}$ Subsequently, this alteration of pharmacokinetics leads to the modification of the pharmacodynamic affecting the efficacy and toxicity of ENMs. ${ }^{87,115,116}$ Therefore, high throughput testing tools provide predictive data that have been proposed to develop more efficient safety assessment protocols for ENMs. ${ }^{117,118}$ The assessment of ENMs toxicity can be categorized into various steps; physicochemical characterization, in vitro assay (cellular and acellular), and in vivo assays. $^{77,119}$ Nevertheless, many of the existing safety assessment standards are not suitable to assess the ENMs safety, due to their lack of a standardized method for characterizing critical physicochemical properties and their corresponding effects on various pathological systems. ${ }^{101-104,120}$ Safety assessment of the ENMs requires a careful look for precise assays considering the distinct physicochemical properties of the ENMs and the potential interference between them and the assay kits. ${ }^{101-104,120}$ However, the exponential growth of ENMs results in their corresponding design complexity and complex physicochemical properties. This exerts difficulties in inaccurate measurements of critical physicochemical parameters in their application in nanomedicines.

In determining the toxicity of ENMs, several studies have proposed various frameworks in performing predictive safety assessment of ENMs. Mirshafiee et al proposed a pyramidal model on the determination of ENMs toxicity, and their suitability in nanomedicine application.

As shown in Figure 5, the hierarchy of ENMs' predictive safety assessment starts with the design and characterizations of ENMs. After that, the ENMs shall be subjected to in vitro safety screening to capture possible toxicities in the ENMs. After the in vitro screening, the nanomaterials will be subjected to in vivo safety assessment. The designed ENMs require to pass both in vitro and in vivo stages before proceeding to nanomedicine applications, including clinical trials, or prototype development. $^{121}$

Fundamentally, in vivo is the research or investigation where work is done within a living organism. This includes

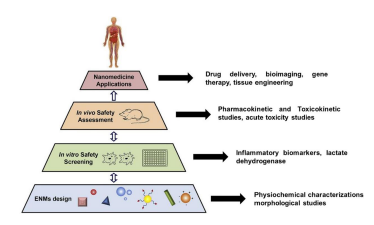

Figure 5 Pyramid model on the determination of ENMs design, production and toxicity assessment.

Notes: Adapted with permission from Mirshafiee V, Jiang W, Sun B, Wang X, Xia T. Facilitating translational nanomedicine via predictive safety assessment. Mol Ther. 2017;25:1522-1530. . ${ }^{121}$ 
studies in animal bodies, systems, or human clinical trials. Meanwhile, in vitro is the research or investigation where work is done outside a living organism. This includes studying cells in culture or antibiotic tests. In toxicity assessment in nanomedicine, in vivo is extensively used to obtain the first-hand safety assessment information of the nanoparticles, as reported by Quarta et $\mathrm{al}^{122}$. In practice, the in vivo toxicology safety assessment of nanomedicine is similar to conventional drugs. First, the pseudo allergy reactions of patients to the active ENM particles shall be characterized, predict, and prevent. This is to mitigate the risk of acute cardiopulmonary distress, which can be lethal to patients. ${ }^{124}$ Prior to clinical trials, preclinical safety and pharmacokinetic evaluation in animals are required by the regulatory bodies. These evaluations must be carried out under good laboratory practice. As reported by $\mathrm{Cicha}$ et al, the required in vivo toxicology tests include (1) safety pharmacology test, (2) pharmacokinetic and toxicokinetic studies, (3) acute toxicity studies, (4) local tolerance studies in rabbit, and (5) genotoxicity studies before proceeding to good manufacturing practice production. ${ }^{124}$

As mentioned earlier, due to the high sensitivity of ENMs' physicochemical properties, the research outcomes on the ENMs' toxicity across various labs are inconsistent. Therefore, it is important to establish a platform, where sharing of toxicity outcome is available among the nanomedicine communities. Fadeel et al proposed a harmonized knowledge infrastructure for the safety, toxicity and harmfulness regulations of ENMs. In the reported work, a co-sharing platform developed based on various principles, including findability, accessibility, interoperability and reusability of data, has been preliminarily proposed. As shown in Figure 6 , the data obtained from students can be transparently shared within the community, assuring the quality, completeness and objectivity of the obtained data. The end-user of the shared data includes modelers, risk assessors, regulators, consumers, which can use the toxicity data as a useful reference in making various regulatory or purchasing decisions. ${ }^{118}$

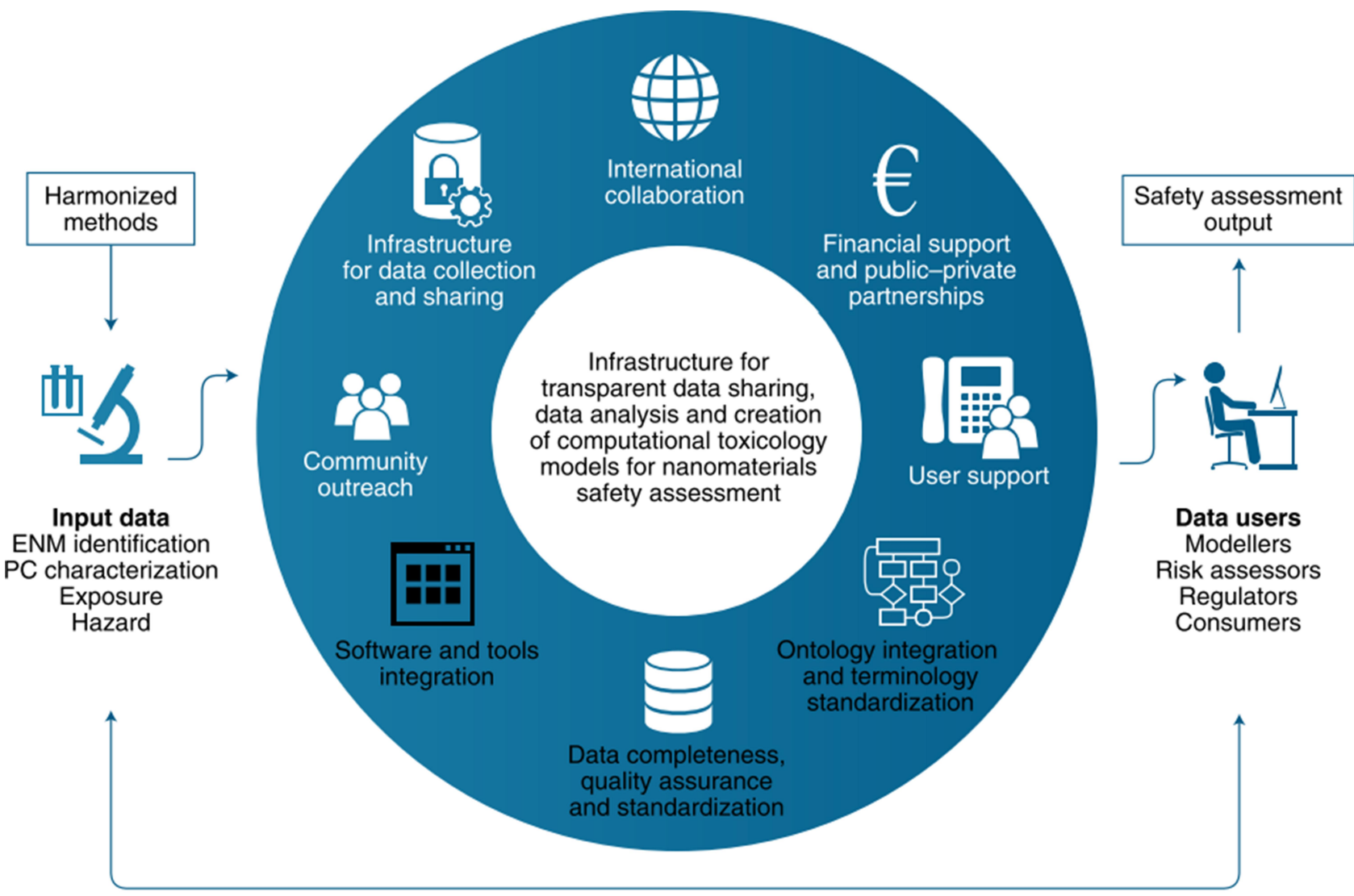

Principles on findability, accessibility, interoperability and reusability of data

Figure 6 Knowledge-sharing platform in assessing the toxicity of ENMs in nanomedicine.

Notes: Reprinted by permission from Springer Nature CustomerService Centre GmbH: Springer Nature; Nature Nanotechnology; Fadeel B, Farcal L, Hardy B, et al. Advanced tools for the safety assessment of nanomaterials. Nat Nanotechnol. 2018;13:537-543; Copyright $2018 .{ }^{118}$ 
In regulating the toxicity data of ENMs, various machine learning algorithms have been developed to better understand and evaluate the toxicity behavior of the ENMs. ${ }^{125}$ These include linear and logistic models, support vector machines (SVM), random forests (RF), classification and regression trees (CART), partial least squares discriminant analysis (PLSDA), linear discriminant analysis (LDA), and artificial neural networks (ANNs). ${ }^{126}$ These approaches are anticipated to produce toxicity prediction with greater accuracy. By implementing machine learning in toxicology studies in nanomedicine, it transforms human's capability to speculate the toxicities from nano-structures under experimental and in vivo condition. Thus, the study of machine learning application in toxicology studies remains a dynamic and diverse manner, where preliminary standardized methodology requires a substantial period of research duration to subside. ${ }^{127}$

As discussed earlier, the study of ENMs in nanomedicine involves a mass number of diverse nanomaterials researches. To build up a predictive modeling algorithm on the nanotoxicity, two primary phases are essential identification of physiochemical properties of ENMs which will cause toxicity issues, and standardized toxicity data collection for possible data analysis and mining. The properties which yield toxicity in ENMs shall be discussed in the next section. For standardize toxicity data collection, ISA-TAB Nano (Investigation Study - Assay - Material Tab-delimited) was introduced to ensure same-page communication of toxicity data across researchers on various ENM species. This is to compile and communicate diversified data in a standardized way. ${ }^{128}$

To realize predictive modeling for ENMs' toxicity, various computational systems and data mining techniques are required. Among the reported computational system, regression analysis is widely used in forecasting and speculating toxicology behavior. ${ }^{129}$ Regression is a simple predictive model that describes the changes in the figures of dependent variables along with independent variables. For example, Horev-Azaria et al reported the usage of the regression technique to predict the toxicology of cobalt nanoparticles and ions. By using regression techniques, the obtained data integrates wells with the in vitro data from five different research groups, where the toxicity behavior can be analyzed based on average threshold values of dose responses. ${ }^{130}$

Besides the regression technique, other computational techniques have also been reported, such as decision trees, support vector machines, and artificial neural networks.
For instance, Gajewicz et al reported the usage of the decision tree model in classifying nanomaterials according to the DF4nanoGrouping scheme. In the reported study, three qualitative classification tree models have been developed for the toxicology predictive model, where small data set predictions are feasible. ${ }^{131}$ Nevertheless, the development of a predictive model for toxicology assessment in nanomedicine is an emerging trend, where much development and investigations are needed.

In general, regulators shared agreement on some physicochemical properties as the important parameters and critical factors for the evaluation of ENMs safety, especially for nanomedicine formulations. ${ }^{42,132}$ The critical factors include particle size distribution (PSD), chemical composition, drug loading capacity and release kinetics. ${ }^{133}$

\section{Critical Factors and Parameters for the Evaluation of ENMs Safety in Nanomedicine}

The nature of cell responses toward ENMs is directly related to their physicochemical properties. ${ }^{71,134,135}$ In nanotoxicology, beyond the description of ENMs uptake pathways with their kinetics (absorption, distribution and clearance) in the body, understanding of the interactions between cell-nanomaterial is more critical. This includes their dependence on the intrinsic and extrinsic properties in altering the nanotoxicity of the ENMs ${ }^{71,95,103,136-138}$ (Figure 7).

As mentioned earlier, the large surface area per mass causes ENMs surface to be more reactive, thermodynamically unstable and increase their biological activity compared to the bulk materials. ${ }^{93}$ This activity is associated with the susceptibility in causing inflammatory and pro-

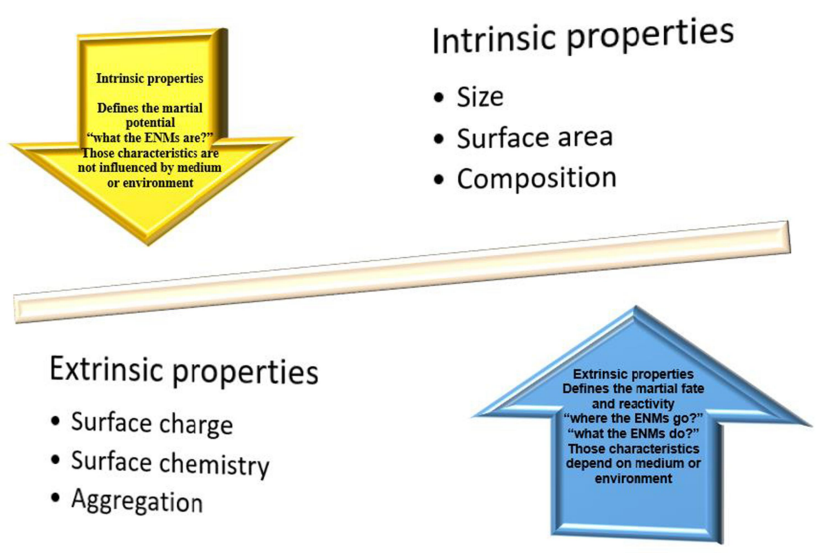

Figure 7 The extrinsic-intrinsic properties balance for the selection of ENM to be used in nanomedicine. 
Table 4 Physiochemical Properties of ENMs and Their Associated Effects and Characterization Methods

\begin{tabular}{|c|c|c|c|}
\hline $\begin{array}{l}\text { Physicochemical } \\
\text { Properties }\end{array}$ & Effects & Characterization Method & Ref. \\
\hline $\begin{array}{l}\text { Size and size } \\
\text { distribution }\end{array}$ & $\begin{array}{l}\text { Effect the body absorption of the ENMs, their } \\
\text { biodistribution and excretion. Determines the } \\
\text { cytotoxic response } \\
\text { Affects the cell uptake and endocytosis process } \\
\text { Altering the ENMs intracellular fate } \\
\text { a common consensus on literature that as the size } \\
\text { of the ENMs become smaller, the degree of } \\
\text { cytotoxicity is greater. }\end{array}$ & $\begin{array}{l}\text { Dynamic light scattering (DLS) } \\
\text { Brunauer-Emmett-Teller (BET) } \\
\text { Nanoparticle tracking analysis } \\
\text { (NTA) } \\
\text { Field flow fractionation (FFF) } \\
\text { coupled sizing detectors (DLS- } \\
\text { multi angle light scattering } \\
\text { [MALS]) } \\
\text { Transmission electron } \\
\text { microscopy (TEM) }\end{array}$ & {$[75,|16| ,1|7| 20,135,136,156,193]$,} \\
\hline $\begin{array}{l}\text { Surface and } \\
\text { morphology }\end{array}$ & $\begin{array}{l}\text { Affects the cell uptake mechanism } \\
\text { cytotoxicity of ENMs depend on the particle's } \\
\text { morphology }\end{array}$ & $\begin{array}{l}\text { FFF-MALS-DLS } \\
\text { FE-SEM } \\
\text { Transmission electron } \\
\text { microscopy (TEM) } \\
\text { Brunauer-Emmett-Teller (BET) }\end{array}$ & {$[31,71,103,137,138,156]$} \\
\hline $\begin{array}{l}\text { Surface coating and } \\
\text { charge on ENMs }\end{array}$ & $\begin{array}{l}\text { ENMs surface coating act as interfaces between } \\
\text { nanostructure-cell } \\
\text { Affects the intrinsic interactions, cell uptake, } \\
\text { cytotoxicity } \\
\text { Determines the ENMs charges cell uptake } \\
\text { positively charged ENMs more effectively lead to } \\
\text { more toxicity effects compared to neutral or } \\
\text { negatively charged ENMs }\end{array}$ & $\begin{array}{l}\text { Zeta Potential analysis } \\
\text { Fourier transform infrared } \\
\text { spectrometer (FTIR) } \\
\text { Transmission electron } \\
\text { microscopy (TEM) } \\
\text { Energy-dispersive X-ray coupled } \\
\text { SEM (SEM-EDX) } \\
\text { X-ray diffraction (XRD) } \\
\text { Raman Spectra }\end{array}$ & {$[31,7|| 03,, \mid 37,138,156]$} \\
\hline
\end{tabular}

oxidant response, potentially exhibit antioxidant activity. ${ }^{31,135,138}$ With the recent advancement in material engineering, achieving a precise synthesis of ENMs with specific functionality and targeted action is possible. There is a various aspect of nanotoxicological responses which depend on their size, surface morphology, charge and composition $^{71,93,137}$ (Table 4).

\section{Physicochemical Characterization Techniques for ENMs Effect of Physicochemical Properties in ENMs on Their Nanotoxicity}

Among ENMs, certain properties define their possible interaction within the biological system and determining cellular response and uptake, their in vivo fate, and toxicity. $^{70,71,78,84,87,93,94,103,137,139}$ Therefore, their physicochemical characterizations in determining the corresponding feasibility in nanomedicine applications. The most critical properties are cluster-size distribution, elemental composition, morphology, surface charge, functionalization and aggregation. ${ }^{136-138,140,141}$
Fundamentally, most in vivo toxicity of ENMs ignited from the production of reactive oxygen species (ROS). A widely-recognized mechanism of ROS production is when Fe-based ENMs are dissolved in aqueous solutions, where the Fe particles act as catalysts for the formation of $\mathrm{OOH}$ and $\mathrm{OH}$ free radicals from $\mathrm{H}_{2} \mathrm{O}_{2}$ molecules. ${ }^{142}$ The occurrence of free radicals from $\mathrm{H}_{2} \mathrm{O}_{2}$ arises from the Fenton reaction, which is induced by the byproduct $(\mathrm{Fe})$ catalyst formation upon biochemical reaction between ENMs and human tissues. For the case of inert nanoparticles, thought spontaneous ROS production is absent, but the production of ROS can occur under pathological conditions. ${ }^{143}$ The production of ROS can damage cells by peroxidizing lipids, altering proteins, disrupting DNA, and finally ending up in cancer. ${ }^{30}$

Among the properties of ENMs, particle size and surface area are crucial in nanotoxicology. As particle size reduces, the corresponding surface area increases, which results in high reactivity ENMs. Both in vitro and clinical studies show that ENMs with small particle sizes with correspondingly large surface areas yield higher ROS 
generation. ${ }^{144}$ This increases the susceptibility of ENMs in entering the biological system of human bodies, which can induce tissue injury and other possible toxicity effects. For example, Jiang et al reported that the binding and activation of membrane receptors highly-correlate with the ENMs particle size. Studying Au nanoparticles between 2 to $100 \mathrm{~nm}$, they discovered that the Au particles play an active role in mediating cell functions, which may simultaneously induce toxicity issues in biological processes. ${ }^{145}$ At the same time, another consideration in altering the particle size of ENMs is the rate of degradation and clearance from the human system. For example, $\mathrm{Au}$ ENMs smaller than $50 \mathrm{~nm}$ cause high toxicity when administered into animal samples, they disperse to nearly all issues (eg heart, lungs, liver, etc.) and accumulate in these respective organs. On the other hand, Au ENMs with 100-200 nm particle sizes cause low toxicity as they can be cleared from the biological system naturally. ${ }^{146}$

Besides particle size, the surface charge of ENMs occupies and decisive role in determining its corresponding toxicity. In principle, the surface charge controls the ion adsorption and alters biological feedback towards particles. At the same time, surface charge influences the agglomeration characteristics of ENMs and their corresponding shapes and sizes. ${ }^{147}$ Typically, positively-charged surfaces are more toxic than negatively charged surfaces, possibly due to the cation affinity towards negatively-charged functional groups on cell membranes. This influences the plasma protein binding, which has a direct effect on the excretion of ENMs from the human body. ${ }^{148}$ For example, Saxena et al reported that acid-functionalized CNTs has a significantly higher toxicity than pristine counterparts, specifically under in vivo condition. This can be attributed to two possible factors, a high surface-to-size ratio of functionalized CNTs, or negatively-charged CNTs which enhances the susceptibility in bioreactions. ${ }^{149}$ Similar outcomes on CNTs were reported by Pietroiusti et al, where acid-treated CNTs have a higher toxicity effect on pregnant mice as compared to pristine CNTs. This can be attributed to the negative charge and low hydrophobicity of functionalized CNTs. ${ }^{150}$

Besides particle size and surface charges, there are several factors in dictating the toxicity of ENMs, including particle shape, composition, coatings, and surface roughness. In terms of particle shape, a study published by Gurr et al discovered that Rutile $\mathrm{TiO}_{2}$ causes oxidation-induced DNA damages and lipid peroxidation; whereas anatase $\mathrm{TiO}_{2}$ has negligible toxicity. ${ }^{151}$ On the other hand, Griffitt et al found that silver- and copper-based ENMs possess significant toxicity, whereas $\mathrm{TiO}_{2}$ has relatively negligible toxicity. ${ }^{152}$ Nevertheless, due to the mass variations of ENMs available in the state-of-the-art, the factors influencing the nanotoxicity of each ENMs are still underexplored, where further investigations are called for. ${ }^{153}$

\section{The Challenge of Physicochemical Properties Characterization}

To date, the existing standard characterization methods listed and recognized by the health agencies are insufficient and often not suitable to characterize the sophisticated ENMs and their potential effect on biological systems. ${ }^{133}$ This can be attributed to the information gaps between the regulatory and research community, caused by the complexity of numerous critical physicochemical properties. For example, the International Organization for Standardization (ISO) guidelines include electron microscopy (EM), dynamic light scattering (DLS), small-angle X-ray scattering (SAXS), atomic force microscopy (AFM) as the standard characterization, forgoing the chemical and elemental composition aspects of the ENMs. ${ }^{120,154}$ Besides, the invalidity issues inherited in some of those methods, applying those methods to the more complex innovative ENMs may require a new or modified method in order to fit newly developed ENMs characterization. ${ }^{120}$ Subsequently, comprehensive, established characterization standards are critical for supporting authorities in making decisions on the feasibility of ENMs in nanomedicines. For that reason, the current research is focusing on the introduction of robust physicochemical and alternative toxicology testing methods with capacity and proven validity to be employed as the future standardized evaluation methods in the field of nanomedicine. $^{70,75,133}$ The hyphenated method is recently proposed as the possible solution, in which, the characterization method is advanced for example by coupling a separation technique with an on-line detection technology. ${ }^{155}$ Other examples include coupling $\mathrm{xx}$ (SEC) or $\mathrm{xx}$ (FFF) with two detectors channeled to characterization systems, such as UVVis, refractive index (RI), or multi-angle light scattering (MALS) for sizing applications. ${ }^{156}$ This has led to an extraordinary improvement and has significantly broadened the applications in the analysis and characterization. ${ }^{120,156-159}$ The addition of on-line DLS with SEC or FFF can overcome the polydispersity limitation of DLS batch measurements. $^{118,120,156,160}$ In addition, the hyphenation of various characterization systems can facilitate more comprehensive characterizations in a single experiment including, mass concentration, composition, molar mass, size and shape of each detected ENMs population. ${ }^{156}$ The International 


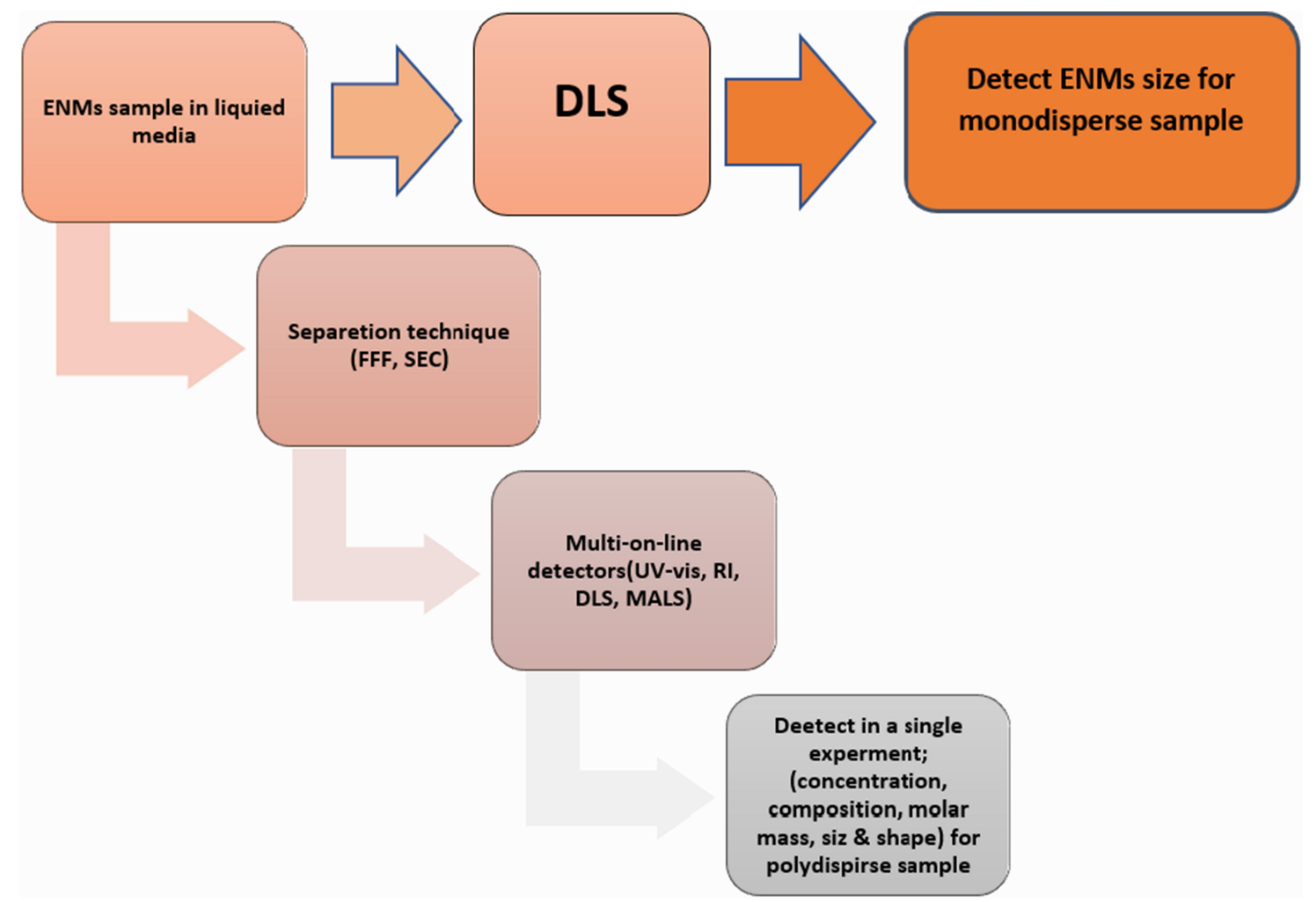

Figure 8 Illustration of the advantage of separation hyphenation with multi-detectors vs DLS technique.

Organization for Standardization (ISO) has recently released the pioneering standard on the FFF application for nanoparticles. ${ }^{154}$ Figure 8 illustrates the hyphenation of the Asymmetric Field flow fractionation (AFFF) method coupled with $\mathrm{xx}$ (PTA), using a series of different detectors.

\section{ENMs Characterization Techniques Particle Tracking Analysis}

Over the past years, particle tracking analysis (PTA), or commonly known as Nanoparticle Tracking Analysis (NTA), is progressively becoming a mainstream technique for characterizing ENMs in a liquid suspension. ${ }^{120,156}$ This is a highresolution analysis technique, rapidly and inexpensively track individual particles measuring their size among multiple individual nanoparticles. ${ }^{120}$ Like DLS, the working principle of PTA involves light scattering and Brownian motion.

PTA possesses many advantages over DLS. PTA is capable of tracking individual particles and calculating their diffusion coefficient. ${ }^{118,133,157}$ Additionally, it can differentiate between two particles or populations with small differences. The working mechanisms of PTA depend highly on the ENMs diffusion coefficient and Brownian motion, or light scattering intensity, enabling it to detect motion changes in molecular scale. ${ }^{133,156,160}$ One of the most prominent advantages of PTA over DLS is overcoming larger particles or aggregates limitation which DLS techniques overwhelmingly bias on the current of the large particles in the sample. ${ }^{161}$ The ability of PTA to track single particles enables secondary peaks detection, which may be undetectable with other conventional methods. ${ }^{161}$ Apart from that, PTA enables the concurrent calculation of the sample concentration in nanoparticle per milliliter $(\mathrm{NPs} / \mathrm{mL}) .{ }^{120,156,157,161}$ Moving forward, the analysis of PTA is further advanced by integrating the finite track length adjustment algorithm to refine the analysis of the polydisperse and multimodal sample through refining isolation and resolution of size distribution peak. ${ }^{156,160}$

Nevertheless, PTA exhibits limitations, specifically when analyzing polydisperse samples. These limitations are related to the camera and the laser set up a dynamic range of PTA, which could lead to measurement errors and inaccuracies. ${ }^{120,157}$ The visualization of tiny particles requires a shorter wavelength, as shorter wavelengths scattered more strongly in contrast to longer wavelengths under Rayleigh and Mei scattering. Analyzing a polydisperse sample using the short wavelength laser $(405 \mathrm{~nm})$ in PTA setups may result in the detection of the smaller components. ${ }^{120,157}$ As a result, it 
overexposes the larger particles which could conceal small particles. $^{162}$

Another limitation of PTA is the role of light scattering potential in determining the accuracy of particles' concentration measurement and size measurements. ${ }^{120,157}$ This operational limit results in higher uncertainty when measuring particles with low refractive indices. To overcome the polydisperse sample analyses limitation by DLS and PTA, a fractionation step before measurement using DLS and MALS detectors coupled with the cloud system, including the asymmetric flow FFF (AF4) or size exclusion chromatography, ${ }^{118,120,156,157}$ is recommended.

\section{Asymmetric Field Flow Fractionation}

Asymmetric flow field-flow fractionation (AF4) can be described as a particle-size characterization system where particles are separated based on size. ${ }^{156,158,160,163}$ In a typical characterization process, ENMs are channeled through a narrow tunnel, in which the parabolic laminar flow profile is obtained. ${ }^{163}$ The narrow tunnel consists of two walls, the impermeable upper wall and the accumulation wall at the bottom, made up of a permeable membrane. The applied separation force is generated through a perpendicular field or crossflow. The particles within the sample are forced by the crossflow in the direction of the accumulation wall while being countered by the Brownian motion. As a result, larger particles will equilibrate around the accumulation wall with reduced diffusion rates decreases and a low-velocity profile throughout the laminar flow. Meanwhile, smaller particles are suspended further away from the accumulation wall, possessing a higher velocity profile as compared to its larger particle counterpart. Consequently, the smaller particles will pass through and elute the tunnel before the larger particles. ${ }^{120,160,163}$ By coupling AF4 with various in-line detectors (eg DLS, multiangle light scattering, refractive index and ultraviolet-visible spectrophotometry) to the smaller particle stream, the determination of several parameters including, hydrodynamic size, purity, and radius of rotation can be realized. AF4 setups have been proposed to analyze polydisperse suspensions in which AF4 first separates the sample fractionating its populations for analysis off-line by the suitable detection technique. ${ }^{156,156,160,163}$

The use of this multipurpose and gentle fractionation technique was effectively used to characterize numerous types of ENMs within nanomedicine applications like liposomes, lipid nanoparticles, polymeric nanoparticles, viruslike particles, metallic nanoparticles and metal oxides. This technique enables various characterizations to be carried out in a biologically relevant environment under their original properties, stability and behavior. ${ }^{118,120,156,158,160,163}$

Despite the previously described advantages, the abovementioned separation-based techniques possess some challenging issues. In general, this approach requires the development of a new method for each corresponding type of ENMs to achieve measurement robustness and accuracy, instead of onesize-fits-all setups for various types of ENMs. Apart from that, to obtain particle size and particle shape data from the system, the particles should be larger than $10 \mathrm{~nm}$ attributing to MALS' limitations for slight isotropic scatterers and the radius of gyration, Rg. However, there have been continuous advancements in AF4 systems by integrating it with a viscometer to facilitate the analysis of ENM flow's intrinsic viscosity, which enables instantaneous measurements of particle sizes of isotropic scatterers. $^{156,158}$

\section{Taylor Dispersion Analysis}

Taylor Dispersion Analysis (TDA) is a microcapillary flow technique, where the ENM sample is pushed through a laminar flow of a stationary phase (buffer). Attributing to the combined effect of convection and radial diffusion, the ENM sample flow is perpendicular to the laminar flow along with the buffer. ${ }^{164}$ This method enables mass-weighted size measurement of ENM samples regardless of the variation of sample population sizes, providing accurate results down to $0.3 \mathrm{~nm}$ scale. ${ }^{165}$ Recently, an automated characterization system commercialized with a UV detector is gaining attention in the industry. The drawback of this system is the interactions between the sample and capillary walls and the sensitivity of the system toward the presence of chromophoric impurities, which can affect the results. ${ }^{165-167}$ Furthermore, TDA is a batch-mode technique which is not effective with polydisperse samples. $^{166-168}$

\section{Tunable Resistive Pulse Sensing}

Tunable resistive pulse sensing (TRPS) is a characterization technique that enables specific particle detection, characterized based-on three important physicochemical parameters simultaneously: particle size, particle concentration and zeta potential. ${ }^{169,170}$ The principle of this technique relies on a variant of resistive pulse sensing (RPS). ${ }^{171}$ Under an applied electrical potential across the membrane, a suspension of particles in aqueous electrolyte media is passed through a single pore in a membrane. When a particle passing the membrane disrupting the generated ionic current, it generates a resistive pulse. ${ }^{169}$ A significant limitation of TRPS as compared to the previously discussed techniques (PTA, AF4, etc.), is the 
calibration requirement. ${ }^{171}$ Extensive and repeated calibrations are required in TRPS, which increases the challenges and time consumed in using TRPS. Nevertheless, both PTA and TRPS exhibit similar performance in the level of accuracy when analyzing tiny particles. ${ }^{172}$

\section{Conclusions}

Despite the rapid development trend in nanotechnology research, the field of nanotoxicology research is growing relatively slow. However, the uprising awareness about the toxicity of engineered nanomaterials (ENMs) in nanotechnology and nanomedicine communities provokes much attention toward nanotoxicology research. Several strategies and frameworks have been proposed in identifying the toxicology of ENMs in nanomedicine, including strategies in nanotoxicology identification and sharing of knowledge among the research and regulatory personnel. Fundamentally, the toxicity of ENMs is caused by several factors. Two primary factors are the physicochemical properties and their associated permeability, which can be defined as their ability to infiltrate through the body to reach cells. ENMs toxicity has been documented at both the molecular and cellular level. From the documented studies, it can be deduced that ENMs' size is one of the important parameters leading to oxidative stress within the cells and to pro-inflammatory response which eventually causes cell death. To understand the toxicity of ENMs, several aspects need to be taken into considerations. These include characterization and understanding of ENMs' physicochemical parameters, the influence of these parameters on ENMs' toxicity, and to minimize their toxicity by developing biocompatible ENMs. The translational research of ENMs in nanomedicine can be fully achieved only when there is enough understanding of their potential risks and hazards, leading to a growing positive perspective for various applications in nanomedicine. However, there are still many challenges to overcome, including the lack of validated characterization methods for ENMs' properties.

\section{Way Forward}

This review addresses the current nanotoxicology in nanomedicine in several aspects: the state-of-the-art of engineered nanomaterials (ENMs) in nanomedicine, the toxicology issues in ENMs, the working framework in developing a toxicology benchmark for ENMs, and technical characterization techniques in determining the toxicity of ENMs. Several directions shall be focused on the nanotoxicology communities of the ENMs as our next steps.

First, the integration of various characterization techniques in determining the toxicology characteristics of ENMs. The current literature has developed extensive researches on studying the toxicity of various ENMs. However, their use in different studies is inconsistent. Thus, it is important to develop integrated characterization techniques to address the comprehensive toxicity information of each ENMs. Second, the internationally recognized standards of qualification on the toxicity of ENMs in nanomedicine. As the toxicity of ENMs are widely varied, and the toxicity of each nanomedicine application requires varied toxicity threshold, the development of standards can be categorized according to their corresponding ENMs/nanomedicine applications. Third, the establishment of a knowledge-sharing platform among the research communities, regulatory parties, and consumers. The data, including toxicity research data and suggested toxicity qualification standards produced by researchers and authorities, shall be transparently shared. Thus, the research communities can steer the toxicology research directed specifically to the needs of the regulatory parties, while the regulatory parties can tweak the existing standards and regulations on toxicity according to the current research findings. At the same time, consumers can make better purchase decisions according to the research outcomes and regulations shared on the knowledge platform.

It is undeniable that many technical details are still underexplored in understanding the toxicity of ENMs in nanomedicine. These include the specific toxicity of derived ENMs and complex ENM/matrix composites. Nevertheless, while technical explorations are irreplaceable, we shall also work on the strategies on integrating the existing knowledge available in the state-of-the-art and develop them into comprehensive toxicity regulation standards or standard-operation-procedures. Thus, the knowledge development, standard regulation, and knowledge sharing of nanotoxicology shall be carried out concurrently in our future work.

\section{Acknowledgments}

This work was supported by Grant Putra Berimpak, UPM/ 800-3/3/1/GPB/2019/9678800, Vot. No. 9678800 Universiti Putra Malaysia. FMA would like to thanks Lim Yu Dian (Faculty of engineering, Nanyang Technological University, Singapore) for the cooperation with revising the manuscript.

\section{Disclosure}

The authors report no conflicts of interest in this work. 


\section{References}

1. Valavanidis A, Vlachogianni T. Engineered nanomaterials for pharmaceutical and biomedical products new trends, benefits and opportunities. Pharm Bioprocess. 2016;4:13.

2. Dublin TD. Research policy. Am J Public Heal Nations Heal. 1959;49:265-268. doi:10.2105/AJPH.49.2.265

3. Analysis, M. Biomaterials and Medical Applications Nanotechnology 2020 Market Analysis. Vol. 3; 2020:2019-2020.

4. Pinto MP, et al. A molecular stratification of chilean gastric cancer patients with potential clinical applicability. Cancers (Basel). 2020;12:1-14.

5. Nikalje AP. Nanotechnology and its applications in medicine. Med Chem (Los Angeles). 2015;5. doi:10.4172/2161-0444.10 00247

6. Rizzo LY, Theek B, Storm G, Kiessling F, Lammers T. Recent progress in nanomedicine: therapeutic, diagnostic and theranostic applications. Curr Opin Biotechnol. 2013;24(6):1159-1166. doi:10.1016/j.copbio.2013.02.020

7. Suri SS, Fenniri H, Singh B. Nanotechnology-based drug delivery systems. J. Occup. Med. Toxicol. 2007;2(1):16. doi:10.1186/17456673-2-16

8. Grewal AS, Lather V, Sharma N, et al. Recent updates on nanomedicine based products: current scenario and future opportunities. Appl Clin Res Clin Trials Regul Aff. 2018;5:132-144. doi:10.2174/2213476X05666180611115135

9. D'Mello SR, Cruz CN, Chen M-L, et al. The evolving landscape of drug products containing nanomaterials in the United States. Nat Nanotechnol. 2017;12:523-529. doi:10.1038/nnano.2017.67

10. Nanomedicine market size worth $\$ 350.8$ billion by 2025 | CAGR: $11.2 \%$. Available from: https://www.grandviewresearch.com/pressrelease/global-nanomedicine-market. Accessed December 17, 2020.

11. Navya PN, Daima HK. Rational engineering of physicochemical properties of nanomaterials for biomedical applications with nanotoxicological perspectives. Nano Converg. 2016;3:1 doi:10.1186/s40580-016-0064-z

12. Peer D, Karp JM, Hong S, et al. Nanocarriers as an emerging platform for cancer therapy. Nat Nanotechnol. 2007;2(12):75 1-760. doi:10.1038/nnano.2007.387

13. Conde J, Bao C, Tan Y, et al. Dual targeted immunotherapy via in vivo delivery of biohybrid RNAi-peptide nanoparticles to tumor-associated macrophages and cancer cells. Adv Funct Mater. 2015;25(27):4183-4194. doi:10.1002/adfm.201501283

14. Dickerson EB, Dreaden EC, Huang X, et al. Gold nanorod assisted near-infrared plasmonic photothermal therapy (PPTT) of squamous cell carcinoma in mice. Cancer Lett. 2008;269 (1):57-66. doi:10.1016/j.canlet.2008.04.026

15. Nam J, Son S, Park KS, et al. Cancer nanomedicine for combination cancer immunotherapy. Nat Rev Mater. 2019;4:398-414. doi:10.1038/s41578-019-0108-1

16. Turchanin A, Weber D, Büenfeld $\mathrm{M}$, et al. Conversion of self-assembled monolayers into nanocrystalline graphene: structure and electric transport. ACS Nano. 2011;5:3896-3904. doi: $10.1021 / \mathrm{nn} 200297 \mathrm{n}$

17. Moshfegh AZ. Nanoparticle catalysts. J Phys D Appl Phys. 2009;42(23):233001. doi:10.1088/0022-3727/42/23/233001

18. Yu X, Zhang X, Zou J, et al. Solvent-tunable microstructures of aligned carbon nanotube films. Adv Mater Interfaces. 2016;3 (17):1-6. doi:10.1002/admi.201600352

19. Conde J, et al. Revisiting 30 years of biofunctionalization and surface chemistry of inorganic nanoparticles for nanomedicine. Front Chemist. 2014;2:48.

20. Chen D, Zhao C, Ye J, et al. In situ biosynthesis of fluorescent platinum nanoclusters: toward self-bioimaging-guided cancer theranostics. ACS Appl Mater Interfaces. 2015;7(32):18163-18 169. doi:10.1021/acsami.5b05805
21. Zhu C, Zhang H, Li W, et al. Suppress orthotopic colon cancer and its metastasis through exact targeting and highly selective drug release by a smart nanomicelle. Biomaterials. 2018;161:144-153. doi:10.1016/j.biomaterials.2018.01.043

22. Patra JK, et al. Nano based drug delivery systems: recent developments and future prospects 10 technology 1007 nanotechnology 03 chemical sciences 0306 physical chemistry (incl. structural) 03 chemical sciences 0303 macromolecular and materials chemistry 11 medical and health sciences 1115 pharmacology and pharmaceutical sciences 09 engineering 0903 biomedical engineering prof Ueli Aebi, Prof Peter Gehr. J Nanobiotechnology. 2018;16:71.

23. Blum AP, Kammeyer JK, Rush AM, et al. Stimuli-responsive nanomaterials for biomedical applications. $J$ Am Chem Soc. 2015;137(6):2140-2154. doi:10.1021/ja510147n

24. Tasso M, Lago Huvelle MA, Diaz Bessone I, Picco AS. Toxicity Assessment of Nanomaterials. Cham: Springer; 2020:383-446. doi:10.1007/978-3-030-39923-8_13

25. Buzea C, Pacheco II, Robbie K. Nanomaterials and nanoparticles: sources and toxicity. Biointerphases. 2007;2:MR17-MR71. doi:10.1116/1.2815690

26. Sims CM, et al. Redox-active nanomaterials for nanomedicine applications. Nanoscale. 2017;9:15226-15251.

27. Krug HF. Nanosafety research-are we on the right track? Angewandte Chemie - International Edition. 2014;53:123 04-12319. doi:10.1002/anie.201403367

28. Kumar V, Lakkaboyana SK, Sharma N, Maitra SS, Hanafiah MM. Nanotoxicology and its remediation. In: Intelligent Nanomaterials for Drug Delivery Applications. Elsevier; 2020:163-178. doi:10.1016/b978-0-12-817830-0.00009-6

29. Sayes CM. Nanotoxicology: Developing a Responsible Technology. Cham: Springer; 2020:43-55. doi:10.1007/978-3-030-19951-7_4

30. Oberdörster G, Oberdörster E, Oberdörster J. Nanotoxicology: an emerging discipline evolving from studies of ultrafine particles. Environ Health Perspect. 2005;113:823-839. doi:10.1289/ehp.7339

31. Podila R, Brown JM. Toxicity of engineered nanomaterials: a physicochemical perspective. $J$ Biochem Mol Toxicol. 2013;27:50-55. doi:10.1002/jbt.21442

32. Srivastava N, Saxena SK. Opportunities in clinical translation and commercialization of nanomedicine. In: NanoBioMedicine. Singapore: Springer; 2020:501-517. doi:10.1007/978-981-32-98989_22

33. Chapter 1 Nanotechnology and nanomaterials. Stud Interface Sci. 2006;23:1-69.

34. Rizvi SAA, Saleh AM. Applications of nanoparticle systems in drug delivery technology. Saudi Pharmaceutical J. 2018;26: 64-70. doi:10.1016/j.jsps.2017.10.012

35. Robinson DKR, Huang L, Guo Y, Porter AL. Forecasting innovation pathways (FIP) for new and emerging science and technologies. Technol Forecast Soc Change. 2013;80:267-285. doi:10.1016/j.techfore.2011.06.004

36. Roco MC, et al. Innovative and responsible governance of nanotechnology for societal development. In: Nanotechnology Research Directions for Societal Needs in 2020. Netherlands: Springer; 2011:561-617. doi:10.1007/978-94-007-1168-6_14

37. Oberdörster G, et al. Principles for characterizing the potential human health effects from exposure to nanomaterials: elements of a screening strategy. In: Particle and Fibre Toxicology. Vol. 2. 2005:1-35.

38. Schirmer K. Mechanisms of nanotoxicity. In: Frontiers of Nanoscience. Vol. 7. Elsevier Ltd; 2014:195-221.

39. Rampado R, Crotti S, Caliceti P, Pucciarelli S, Agostini M. Recent advances in understanding the protein corona of nanoparticles and in the formulation of "Stealthy" Nanomaterials. Front Bioengineer Biotechnol. 2020. doi:10.3389/fbioe.2020.00166

40. Wright PF. Potential risks and benefits of nanotechnology: perceptions of risk in sunscreens. Med J Aust. 2016;204:369-370. doi:10.5694/mja15.01128 
41. Khan AU, Khan M, Cho MH, Khan MM. Selected nanotechnologies and nanostructures for drug delivery, nanomedicine and cure. Bioprocess Biosyst Eng. 2020;43(8):1339-1357. doi:10.10 07/s00449-020-02330-8

42. Pruyn SA, Rajabi M, Adeyeye M, Mousa SA. Pharmaceutical applications of water-soluble polymers in nanomedicine and drug delivery. In: The Road from Nanomedicine to Precision Medicine. Jenny Stanford Publishing; 2020:299-334. doi:10.1201/97804 29295010-7

43. Martinelli C, Pucci C, Ciofani G. Nanostructured carriers as innovative tools for cancer diagnosis and therapy. APL Bioengineering. 2019;3:11502. doi:10.1063/1.5079943

44. Bremer-Hoffmann S, Halamoda-Kenzaoui B, Borgos SE. Identification of regulatory needs for nanomedicines. J Interdiscip Nanomedicine. 2018;3:4-15. doi:10.1002/jin2.34

45. Bobo D, Robinson KJ, Islam J, Thurecht KJ, Corrie SR. Nanoparticle-based medicines: a review of FDA-approved materials and clinical trials to date. Pharm Res. 2016;33:2373-2387. doi:10.1007/s11095-016-1958-5

46. Oerlemans C, Bult W, Bos M, et al. Polymeric micelles in anticancer therapy: targeting, imaging and triggered release. Pharm. Res. 2010;27:2569-2589. doi:10.1007/s11095-010-0233-4

47. Anselmo AC, Mitragotri S. Nanoparticles in the clinic: An update. Bioeng Transl Med. 2019;4(3):e10143

48. Taylor DD, Gercel-Taylor C. MicroRNA signatures of tumor-derived exosomes as diagnostic biomarkers of ovarian cancer. Gynecol Oncol. 2008;110:13-21. doi:10.1016/j.ygyno. 2008.04.033

49. Allen TM, Cullis PR. Liposomal drug delivery systems: from concept to clinical applications. Adv Drug Deliv Rev. 2013;65:36-48. doi:10.1016/j.addr.2012.09.037

50. Yang M, Xie S, Adhikari VP, et al. The synergistic fungicidal effect of low-frequency and low-intensity ultrasound with amphotericin B-loaded nanoparticles on C. albicans in vitro. Int J Pharm. 2018;542:232-241. doi:10.1016/j.ijpharm.2018.03.033

51. Wang-Gillam A, Li C-P, Bodoky G, et al. Nanoliposomal irinotecan with fluorouracil and folinic acid in metastatic pancreatic cancer after previous gemcitabine-based therapy (NAPOLI-1): a global, randomised, open-label, phase 3 trial. Lancet. 2016;387:545-557. doi:10.1016/S0140-6736(15)00986-1

52. Shegokar R, Müller RH. Nanocrystals: industrially feasible multifunctional formulation technology for poorly soluble actives. Int J Pharm. 2010;399:129-139. doi:10.1016/j.ijpharm.2010.07.044

53. van der Meel R, Sulheim E, Shi Y, et al. Smart cancer nanomedicine. Nat Nanotechnol. 2019;14:1007-1017. doi:10.10 38/s41565-019-0567-y

54. Hare JI, Lammers T, Ashford MB, et al. Challenges and strategies in anti-cancer nanomedicine development: an industry perspective. Adv Drug Deliv Rev. 2017;108:25-38. doi:10.1016/ j.addr.2016.04.025

55. Azuaje F. Artificial intelligence for precision oncology: beyond patient stratification. Npj Precis Oncol. 2019;3:1-5. doi:10.1038/ s41698-018-0074-x

56. Ho D, Wang P, Kee T. Artificial intelligence in nanomedicine. Nanoscale Horizons. 2019;4:f365-377. doi:10.1039/C8NH00233A

57. Sahin U, Türeci Ö. Personalized vaccines for cancer immunotherapy. Science (80-). 2018;359:1355-1360. doi:10.1126/science.aar7112

58. Chauhan VP, Martin JD, Liu H, et al. Angiotensin inhibition enhances drug delivery and potentiates chemotherapy by decompressing tumour blood vessels. Nat Commun. 2013;4. doi:10.1038/ncomms 3516

59. Lu J, Liu X, Liao Y-P, et al. Nano-enabled pancreas cancer immunotherapy using immunogenic cell death and reversing immunosuppression. Nat Commun. 2017;8. doi:10.1038/s41467017-01651-9
60. Mehra NK, Cai D, Kuo L, Hein T, Palakurthi S. Safety and toxicity of nanomaterials for ocular drug delivery applications. Nanotoxicology. 2016;10:836-860. doi:10.3109/17435390.2016.1153165

61. Eleraky NE, Allam A, Hassan SB, Omar MM. Nanomedicine fight against antibacterial resistance: an overview of the recent pharmaceutical innovations. Pharmaceutics. 2020;12:1-51. doi:10.3390/pharmaceutics12020142

62. Alavi M, Webster TJ. Nano liposomal and cubosomal formulations with platinum-based anticancer agents: therapeutic advances and challenges. Nanomedicine. 2020;15:2399-2410. doi:10.2217/ nnm-2020-0199

63. Alavi M, Varma RS. Overview of novel strategies for the delivery of anthracyclines to cancer cells by liposomal and polymeric nanoformulations. Int J Biol Macromol. 2020;164:2197-2203. doi:10.1016/j.ijbiomac.2020.07.274

64. Wang C, Yu Y, Irfan M, et al. Rational design of DNA framework-based hybrid nanomaterials for anticancer drug delivery. Small. 2020;16:1-9. doi:10.1002/smll.202002578

65. Prasad M, Lambe UP, Brar B, et al. Nanotherapeutics: an insight into healthcare and multi-dimensional applications in medical sector of the modern world. Biomed Pharmacother. 2018;97:1521-1537. doi:10.1016/j.biopha.2017.11.026

66. Alavi M, Karimi N. Ultrasound assisted-phytofabricated $\mathrm{Fe} 3 \mathrm{O} 4$ NPs with antioxidant properties and antibacterial effects on growth, biofilm formation, and spreading ability of multidrug resistant bacteria. Artif Cells Nanomedicine Biotechnol. 2019;47:2405-2423. doi:10.1080/21691401.201 9.1624560

67. Alavi M, Rai M. Recent progress in nanoformulations of silver nanoparticles with cellulose, chitosan, and alginic acid biopolymers for antibacterial applications. Appl Microbiol Biotechnol. 2019;103:8669-8676. doi:10.1007/s00253-019-10126-4

68. Alavi M, Jabari E, Jabbari E. Functionalized carbon-based nanomaterials and quantum dots with antibacterial activity: a review. Expert Rev Anti Infec Thert. 2020;1-10. doi:10.1080/14787210. 2020.1810569

69. Szakal C, Roberts SM, Westerhoff P, et al. Measurement of nanomaterials in foods: integrative consideration of challenges and future prospects. ACS Nano. 2014;8:3128-3135. doi:10.10 21/nn501108g

70. Radomska A, Leszczyszyn J, Radomski MW. The nanopharmacology and nanotoxicology of nanomaterials: new opportunities and challenges. Adv Clin Exp Med. 2016;25:151-162. doi:10.17 219/acem/60879

71. Anuje M, Sivan A, Khot VM, Pawaskar PN. Cellular interaction and toxicity of nanostructures. In: Nanomedicines for Breast Cancer Theranostics. Elsevier; 2020:193-243. doi:10.1016/ b978-0-12-820016-2.00010-0

72. Sanjay SS. Precautions to avoid consequences leading to nanotoxification. In: Nanoparticles in Medicine. Singapore: Springer;2020:201-220. doi:10.1007/978-981-13-8954-2_8

73. Cataldi M, Vigliotti C, Mosca T, Cammarota M, Capone D. Emerging role of the spleen in the pharmacokinetics of monoclonal antibodies, nanoparticles and exosomes. Int $\mathrm{J} \mathrm{Mol} \mathrm{Sci}$. 2017;18:1249. doi:10.3390/ijms 18061249

74. Ibrahim K, Al-Mutary M, Bakhiet A, Khan H. Histopathology of the liver, kidney, and spleen of mice exposed to gold nanoparticles. Molecules. 2018;23:1848. doi:10.3390/molecules 23081848

75. Kumar A, Kumar P, Anandan A, et al. Engineered nanomaterials: knowledge gaps in fate, exposure, toxicity, and future directions. J Nanomater. 2014;2014:1-16. doi:10.1155/2014/130198

76. De Matteis V. Exposure to inorganic nanoparticles: routes of entry, immune response, biodistribution and in vitro/in vivo toxicity evaluation. Toxics. 2017;5:29. doi:10.3390/toxics5040029 
77. Oberdörster G, Kuhlbusch TAJ. In vivo effects: methodologies and biokinetics of inhaled nanomaterials. NanoImpact. 2018;10:38-60. doi:10.1016/j.impact.2017.10.007

78. Shah JN, Shah AP, Shah HJ, Sutariya VB. Biointeractions of Nanomaterials. Biointeractions of Nanomaterials. CRC Press; 2014. doi:10.1201/b17191

79. Qiao R, Jia Q, Hüwel S, et al. Receptor-mediated delivery of magnetic nanoparticles across the blood-brain barrier. ACS Nano. 2012;6:3304-3310. doi:10.1021/nn300240p

80. Busquets M, Espargaró A, Sabaté R, Estelrich J. Magnetic nanoparticles cross the blood-brain barrier: when physics rises to a challenge. Nanomaterials. 2015;5:2231-2248. doi:10.3390/nano 5042231

81. Thangadurai TD, Manjubaashini N, Thomas S, Maria HJ. Fundamentals of Nanostructures. Cham: Springer; 2020:29-45. doi:10.1007/978-3-030-26145-0_3

82. Bergin IL, Witzmann FA. Nanoparticle toxicity by the gastrointestinal route: evidence and knowledge gaps. Int J Biomed Nanosci Nanotechnol. 2013;3:163. doi:10.1504/IJBNN.2013.054515

83. Zhou X, Liu Y, Wang X, Li X, Xiao B. Effect of particle size on the cellular uptake and anti-inflammatory activity of oral nanotherapeutics. Colloids Surfaces B Biointerfaces. 2020; 187:110880. doi:10.1016/j.colsurfb.2020.110880

84. Sahu SC, Casciano DA. Nanotoxicity: From in vivo and in vitro Models to Health Risks. 2009. doi:10.1002/9780470747803

85. Fernández-Bertólez N, Costa C, Bessa MJ, et al. Assessment of oxidative damage induced by iron oxide nanoparticles on different nervous system cells. Mutat Res Genet Toxicol Environ Mutagen. 2019;845:402989. doi:10.1016/j.mrgentox.2018.11.013

86. Dhawan A, Anderson D, Shanker R. Nanotoxicology: Experimental and Computational Perspectives. 2017.

87. Onoue S, Yamada S, Chan K. Nanodrugs: pharmacokinetics and safety. Int J Nanomedicine. 2014;9:1025. doi:10.2147/IJN.S38378

88. Fard JK, Jafari S, Eghbal MA. A review of molecular mechanisms involved in toxicity of nanoparticles. Adv Pharm Bull. 2015;5:447-454. doi:10.15171/apb.2015.061

89. Zhao H, Li L, Zhan H, Chu Y, Sun B. Mechanistic understanding of the engineered nanomaterial-induced toxicity on kidney. J Nanomater. 2019;2019:1-12. doi:10.1155/2019/2954853

90. Bedard K, Krause KH. The NOX family of ROS-generating NADPH oxidases: physiology and pathophysiology. Physiol Rev. 2007;87:245-313.

91. Chen Q, Moghaddas S, Hoppel CL, Lesnefsky EJ. Ischemic defects in the electron transport chain increase the production of reactive oxygen species from isolated rat heart mitochondria. Am J Physiol - Cell Physiol. 2008;294:460-467. doi:10.1152/ajpcell. 00211.2007

92. Johnston HJ, Hutchison G, Christensen FM, et al. A review of the in vivo and in vitro toxicity of silver and gold particulates: particle attributes and biological mechanisms responsible for the observed toxicity. Crit Rev Toxicol. 2010;40:328-346. doi:10.31 09/10408440903453074

93. Sukhanova A, Bozrova S, Sokolov P, et al. Dependence of nanoparticle toxicity on their physical and chemical properties. Nanoscale Res Lett. 2018;13:1-21. doi:10.1186/s11671-0182457-x

94. Kumar A, Aileen Senapati V, Dhawan A. Chapter 4: protocols for in vitro and in vivo toxicity assessment of engineered nanoparticles. In: Issues in Toxicology. Vol. 2018. 2018:94-132.

95. Johnston LJ, Gonzalez-Rojano N, Wilkinson KJ, Xing B. Key challenges for evaluation of the safety of engineered nanomaterials. Nanolmpact. 2020;18:100219. doi:10.1016/j. impact.2020.100219

96. Gamboa JM, Leong KW. In vitro and in vivo models for the study of oral delivery of nanoparticles. Adv Drug Deliv Rev. 2013;65:800-810. doi:10.1016/j.addr.2013.01.003
97. Lee J, Lilly GD, Doty RC, Podsiadlo P, Kotov NA. In vitro toxicity testing of nanoparticles in 3D cell culture. Small. 2009;5.

98. Kumar V, Kumari A, Guleria P, Yadav SK. Evaluating the toxicity of selected types of nanochemicals. Rev Environ Contam Toxicol. 2012;215:39-121. doi:10.1007/978-1-4614-1463-6_2

99. Das R, Leo BF, Murphy F. The toxic truth about carbon nanotubes in water purification: a perspective view. Nanoscale Res Lett. 2018;13:183. doi:10.1186/s11671-018-2589-z

100. Tomalia DA, Nixon LS, Hedstrand DM. Engineering critical nanoscale design parameters (CNDPs): A strategy for developing effective nanomedicine therapies and assessing quantitative nanoscale structure-activity relationships (QNSARs). In: Pharmaceutical Applications of Dendrimers. Elsevier; 2019: 3-47. doi:10.1016/B978-0-12-814527-2.00001-9

101. Vetten MA, Gulumian M. Interference of gold nanoparticles with in vitro endotoxin detection assays. Curr Nanosci. 2018. doi:10.2174/1573413715666181212120013

102. Ostermann M, Sauter A, Xue Y, et al. Label-free impedance flow cytometry for nanotoxicity screening. Sci. Rep. 2020;10:142. doi:10.1038/s41598-019-56705-3

103. Palacios-Hernandez T, Diaz-Diestra DM, Nguyen AK, et al. Cytotoxicity, cellular uptake and apoptotic responses in human coronary artery endothelial cells exposed to ultrasmall superparamagnetic iron oxide nanoparticles. J. Appl. Toxicol. 2020;40: 918-930. doi:10.1002/jat.3953

104. Shah J, Bhagat S, Singh S. Standard biological assays to estimate nanoparticle toxicity and biodistribution. In: Nanotoxicity. Vols. 71-104. Elsevier; 2020. doi:10.1016/b9780-12-819943-5.00004-x

105. Sehgal SN, Camardo JS, Scarola JA, Maida BT. Rapamycin (sirolimus, rapamune). In: Current Opinion in Nephrology and Hypertension. Vol. 4. 1995:482-487.

106. Karabasz A, Szczepanowicz K, Cierniak A, Bereta J, Bzowska M. In vitro toxicity studies of biodegradable, polyelectrolyte nanocapsules. Int J Nanomedicine. 2018;13:5159-5172. doi:10. 2147/IJN.S169120

107. Zhang Y, Cao X, Liang T, Tong Z. Acid/light dual-responsive biodegradable polymeric nanocarriers for efficient intracellular drug delivery. Polym Bull. 2019;76:1775-1792. doi:10.1007/ s00289-018-2470-3

108. Su S, Kang PM. Systemic review of biodegradable nanomaterials in nanomedicine. Nanomaterials. 2020;10(4):656. doi:10.3390/ nano 10040656

109. Ilinskaya AN, Dobrovolskaia MA. Nanoparticles and the blood coagulation system. Part II: safety concerns. Nanomedicine. 2013;8:969-981. doi:10.2217/nnm.13.49

110. Sulheim E, et al. Cytotoxicity of poly(Alkyl cyanoacrylate) nanoparticles. International Journal of Molecular Sciences. 2017;18(11). doi:10.3390/ijms18112454

111. Kim SY, Lee YM. Taxol-loaded block copolymer nanospheres composed of methoxy poly(ethylene glycol) and poly( $\varepsilon$ caprolactone) as novel anticancer drug carriers. Biomaterials. 2001;22:1697-1704. doi:10.1016/S0142-9612(00)00292-1

112. Hurst HE, Martin MD. Toxicology. In Pharmacology and Therapeutics for Dentistry. Seventh. Elsevier; 2017:603-620. doi:10.1016/B978-0-323-39307-2.00040-0

113. Oberdörster G, Stone V, Donaldson K. Toxicology of nanoparticles: A historical perspective. In: Nanotoxicology. Vol. 1. 2007:2-25.

114. Spoo W. Concepts and terminology. In: Clinical Veterinary Toxicology. Elsevier; 2004:2-7. doi:10.1016/b0-32-301125-x/ 50004-2

115. Rodallec A, Benzekry S, Lacarelle B, Ciccolini J, Fanciullino R. Pharmacokinetics variability: why nanoparticles are not just magic-bullets in oncology. Crit Rev Oncol Hematol. 2018;129:1-12. doi:10.1016/j.critrevonc.2018.06.008 
116. Li SD, Huang L. Pharmacokinetics and biodistribution of nanoparticles. In: Molecular Pharmaceutics. Vol. 5. Mol Pharm; 2008:496-504.

117. Nel AE. Implementation of alternative test strategies for the safety assessment of engineered nanomaterials. J Intern Med. 2013;274:561-577. doi:10.1111/joim.12109

118. Fadeel B, Farcal L, Hardy B, et al. Advanced tools for the safety assessment of nanomaterials. Nat Nanotechnol. 2018;13:537-543. doi:10.1038/s41565-018-0185-0

119. Romeo D, Salieri B, Hischier R, Nowack B, Wick P. An integrated pathway based on in vitro data for the human hazard assessment of nanomaterials. Environ Int. 2020;137:105505. doi:10.1016/j.envint.2020.105505

120. Gioria S, Caputo F, Urbán P, et al. Are existing standard methods suitable for the evaluation of nanomedicines: some case studies. Nanomedicine. 2018;13:539-554. doi:10.2217/nnm-2017-0338

121. Mirshafiee V, Jiang W, Sun B, Wang X, Xia T. Facilitating translational nanomedicine via predictive safety assessment. Mol Ther. 2017;25:1522-1530. doi:10.1016/j.ymthe.2017.03.011

122. Quarta A, Piccirillo C, Mandriota G, Di Corato R. Nanoheterostructures (NHS) and their applications in nanomedicine: focusing on in vivo studies. Materials (Basel). 2019;12:1-37. doi:10.3390/ma12010139

123. Sukhova GK, Williams JK, Libby P. Statins reduce inflammation in atheroma of nonhuman primates independent of effects on serum cholesterol. Arterioscler Thromb Vasc Biol. 2002;22: 1452-1458. doi:10.1161/01.ATV.0000030360.72503.56

124. Cicha I, Chauvierre C, Texier I, et al. From design to the clinic: practical guidelines for translating cardiovascular nanomedicine. Cardiovasc. Res. 2018;114:1714-1727. doi:10.1093/cvr/cvy219

125. Serra A, Fratello M, Cattelani L, et al. Transcriptomics in toxicogenomics, part III: data modelling for risk assessment. Nanomaterials. 2020;10:1-26. doi:10.3390/nano10040708

126. Dutta A, Dubey T, Singh KK, Anand A. SpliceVec: distributed feature representations for splice junction prediction. Comput Biol Chem. 2018;74:434-441. doi:10.1016/j.compbiolchem.2018.03.009

127. Furxhi I, Murphy F, Mullins M, Arvanitis A, Poland CA. Practices and trends of machine learning application in nanotoxicology. Nanomaterials. 2020;10:1-32. doi:10.3390/nano10010116

128. Thomas DG, Gaheen S, Harper SL, et al. ISA-TAB-nano: a specification for sharing nanomaterial research data in spreadsheet-based format. BMC Biotechnol. 2013;13:2. doi:10.11 86/1472-6750-13-2

129. Eriksson L, Johansson E. Multivariate design and modeling in QSAR. Chemom Intell Lab Syst. 1996;34:1-19. doi:10.1016/ 0169-7439(96)00023-8

130. Horev-Azaria L, Kirkpatrick CJ, Korenstein R, et al. Predictive toxicology of cobalt nanoparticles and ions: comparative in vitro study of different cellular models using methods of knowledge discovery from data. Toxicol. Sci. 2011;122:489-501. doi:10.10 93/toxsci/kfr124

131. Gajewicz A, Puzyn T, Odziomek K, et al. Decision tree models to classify nanomaterials according to the DF4nanoGrouping scheme. Nanotoxicology. 2018;12:1-17. doi:10.1080/17435390. 2017.1415388

132. Hund-Rinke K, Herrchen M, Schlich K, Schwirn K, Völker D. Test strategy for assessing the risks of nanomaterials in the environment considering general regulatory procedures. Environ Sci Eur. 2015;27:1-12. doi:10.1186/s12302-015-0053-6

133. Gioria S, et al. Are existing standard methods suitable for the evaluation of nanomedicines: some case studies. In: Nanomedicine. Vol. 13. 2018:539-554.

134. You DJ, Lee HY, Bonner JC. Macrophages: first innate immune responders to nanomaterials. In: Molecular and Integrative Toxicology. Springer Science+Business Media B.V; 2020:15-34. doi:10.1007/978-3-030-33962-3_2
135. Zhang T, Gaffrey MJ, Qian WJ, Thrall BD. Oxidative stress and redox modifications in nanomaterial-cellular interactions. In: Molecular and Integrative Toxicology. Springer Science+Business Media B.V; 2020:127-148. doi:10.1007/978-3-030-33962-3_8

136. Zhu M, Nie G, Meng H, et al. Physicochemical properties determine nanomaterial cellular uptake, transport, and fate. Acc. Chem. Res. 2013;46:622-631. doi:10.1021/ar300031y

137. Hou WC, Westerhoff P, Posner JD. Biological accumulation of engineered nanomaterials: a review of current knowledge. Environmental Sciences: Processes and Impacts. 2013;15:103-122.

138. Zhu M, Perrett S, Nie G. Understanding the particokinetics of engineered nanomaterials for safe and effective therapeutic applications. Small. 2013;9:1619-1634. doi:10.1002/smll.201201630

139. Zamay GS, Zamay TN, Lukyanenko KA, Kichkailo AS. Aptamers increase biocompatibility and reduce the toxicity of magnetic nanoparticles used in biomedicine. Biomedicines. 2020;8:59. doi:10.3390/biomedicines8030059

140. Lundqvist M, Stigler J, Elia G, et al. Nanoparticle size and surface properties determine the protein corona with possible implications for biological impacts. Proc. Natl. Acad. Sci. U. S. A. 2008;105:14265-14270. doi:10.1073/pnas.0805135105

141. Gatoo MA, Naseem S, Arfat MY, et al. Physicochemical properties of nanomaterials: implication in associated toxic manifestations. Biomed Res Int. 2014;2014:1-8. doi:10.1155/2014/498420

142. Nel A, Xia T, Mädler L, Li N. Toxic potential of materials at the nanolevel. Science (80-). 2006;311:622-627. doi:10.1126/science. 1114397

143. Xia T, Kovochich M, Brant J, et al. Comparison of the abilities of ambient and manufactured nanoparticles to induce cellular toxicity according to an oxidative stress paradigm. Nano Lett. 2006;6:1794-1807. doi:10.1021/nl061025k

144. Suen WLL, Chau Y. Size-dependent internalisation of folate-decorated nanoparticles via the pathways of clathrin and caveolae-mediated endocytosis in ARPE-19 cells. J Pharm Pharmacol. 2014;66:564-573. doi:10.1111/jphp.12134

145. Jiang W, Kim BYS, Rutka JT, Chan WCW. Nanoparticlemediated cellular response is size-dependent. Nat Nanotechnol. 2008;3:145-150. doi:10.1038/nnano.2008.30

146. Sonavane G, Tomoda K, Makino K. Biodistribution of colloidal gold nanoparticles after intravenous administration: effect of particle size. Colloids Surfaces B Biointerfaces. 2008;66:274-280. doi:10.1016/j.colsurfb.2008.07.004

147. Hoshino A, Fujioka K, Oku T, et al. Physicochemical properties and cellular toxicity of nanocrystal quantum dots depend on their surface modification. Nano Lett. 2004;4:2163-2169. doi:10.1021/ nl048715d

148. Goodman CM, McCusker CD, Yilmaz T, Rotello VM. Toxicity of gold nanoparticles functionalized with cationic and anionic side chains. Bioconjug Chem. 2004;15:897-900. doi:10.1021/ bc049951i

149. Saxena RK, Williams W, Mcgee JK, et al. Enhanced in vitro and in vivo toxicity of poly-dispersed acid-functionalized single-wall carbon nanotubes. Nanotoxicology. 2007;1:291-300. doi:10.1080/ 17435390701803110

150. Pietroiusti A, Massimiani M, Fenoglio I, et al. Low doses of pristine and oxidized single-wall carbon nanotubes affect mammalian embryonic development. ACS Nano. 2011;5:4624-4633. doi:10.1021/nn200372g

151. Gurr JR, Wang ASS, Chen CH, Jan KY. Ultrafine titanium dioxide particles in the absence of photoactivation can induce oxidative damage to human bronchial epithelial cells. Toxicology. 2005;213:66-73. doi:10.1016/j.tox.2005.05.007

152. Griffitt RJ, Luo J, Gao J, Bonzongo JC, Barber DS. Effects of particle composition and species on toxicity of metallic nanomaterials in aquatic organisms. Environ Toxicol Chem. 2008;27:1972-1978. doi:10.1897/08-002.1 
153. Sharifi S, et al. Toxicity of nanomaterials. Chem Soc Rev. 2016;41:2323-2343.

154. Halamoda-Kenzaoui B, Holzwarth U, Roebben G, Bogni A, Bremer-Hoffmann S. Mapping of the available standards against the regulatory needs for nanomedicines. Wiley Interdiscip Rev Nanomedicine Nanobiotechnology. 2019;11:e1531. doi:10.1002/ wnan. 1531

155. Patel K, Patel J, Patel M, Rajput G, Patel H. Introduction to hyphenated techniques and their applications in pharmacy. Pharm Methods. 2010;1:2. doi:10.4103/2229-4708.72222

156. Clogston JD, Hackley VA, Prina-Mello A, et al. Sizing up the next generation of nanomedicines. Pharm Res. 2020;37. doi: 10.1007/s11095-019-2736-y

157. Hole P. Particle Tracking Analysis (PTA). In: Characterization of Nanoparticles: Measurement Processes for Nanoparticles. Elsevier; 2019:79-96. doi:10.1016/B978-0-12-814182-3.00007-9

158. Hu Y, Crist RM, Clogston JD. The utility of asymmetric flow field-flow fractionation for preclinical characterization of nanomedicines. Anal Bioanal Chem. 2020;412:425-438. doi:10. 1007/s00216-019-02252-9

159. Sahin E, Roberts CJ. Size-exclusion chromatography with multi-angle light scattering for elucidating protein aggregation mechanisms. Methods Mol Biol. 2012;899:403-423.

160. Klein M, Menta M, Dacoba TG, et al. Advanced nanomedicine characterization by DLS and AF4-UV-MALS: application to a HIV nanovaccine. J. Pharm. Biomed. Anal. 2020;179:113017. doi:10.1016/j.jpba.2019.113017

161. Filipe V, Hawe A, Jiskoot W. Critical evaluation of nanoparticle tracking analysis (NTA) by NanoSight for the measurement of nanoparticles and protein aggregates. Pharm Res. 2010;27: 796-810. doi:10.1007/s11095-010-0073-2

162. Gruia F, Parupudi A, Polozova A. Practical considerations for detection and characterization of sub-micron particles in protein solutions by nanoparticle tracking analysis. PDA J Pharm Sci Technol. 2015;69:427-439. doi:10.5731/pdajpst.2015.01051

163. Zattoni A, Rambaldi DC, Reschiglian P, et al. Asymmetrical flow field-flow fractionation with multi-angle light scattering detection for the analysis of structured nanoparticles. $J$ Chromatogr A. 2009;1216:9106-9112. doi:10.1016/j.chroma.2009.06.037

164. Chamieh J, Cottet H. Size-based characterisation of nanomaterials by Taylor dispersion analysis. In: Colloid and Interface Science in Pharmaceutical Research and Development. 2014. doi:10.1016/ B978-0-444-62614-1.00009-0

165. Chamieh J, Leclercq L, Martin M, et al. Limits in size of taylor dispersion analysis: representation of the different hydrodynamic regimes and application to the size-characterization of cubosomes. Anal. Chem. 2017;89(24):13487-13493. doi:10.10 21/acs.analchem.7b03806

166. Cottet H, Biron JP, Martin M. Taylor dispersion analysis of mixtures. Anal. Chem. 2007;79(23):9066-9073. doi:10.1021/ac071018w

167. Urban DA, Milosevic AM, Bossert D, et al. Taylor dispersion of inorganic nanoparticles and comparison to dynamic light scattering and transmission electron microscopy. Colloids Interface Sci. Commun. 2018;22:29-33. doi:10.1016/j.colcom.2017.12.001

168. Hulse WL, Gray J, Forbes RT. Evaluating the inter and intra batch variability of protein aggregation behaviour using Taylor dispersion analysis and dynamic light scattering. Int. J. Pharm. 2013;453(2):351-357. doi:10.1016/j.ijpharm.2013.05.062

169. Weatherall E, Willmott GR. Applications of tunable resistive pulse sensing. Analyst. 2015;140(10):3318-3334. doi:10.1039/ c4an $02270 \mathrm{j}$

170. Pal AK, Aalaei I, Gadde S, et al. High resolution characterization of engineered nanomaterial dispersions in complex media using tunable resistive pulse sensing technology. ACS Nano. 2014;8 (9):9003-9015. doi:10.1021/nn502219q
171. Pei Y, Vogel R, Minelli C. Tunable resistive pulse sensing (TRPS). In: Characterization of Nanoparticles: Measurement Processes for Nanoparticles. 2019. doi:10.1016/B978-0-12814182-3.00009-2

172. Mørk M, Pedersen S, Botha J, Lund SM, Kristensen SR. Preanalytical, analytical, and biological variation of blood plasma submicron particle levels measured with nanoparticle tracking analysis and tunable resistive pulse sensing. Scand. J. Clin. Lab. Invest. 2016;76(5):349-360. doi:10.1080/00365513.2016.1178801

173. Su QP, et al. CTCF-mediated chromatin structures dictate the spatiotemporal propagation of replication foci. bioRxiv. 2019. doi: $10.1101 / 525915$

174. Pentyala S, Muller J, Tumillo T, et al. A novel point-of-care biomarker recognition method: validation by detecting marker for diabetic nephropathy. Diagnostics. 2015;5:177-188. doi:10. 3390/diagnostics5020177

175. Guzman JMCC, Hsu SM, Chuang HS. Colorimetric diagnostic capillary enabled by size sieving in a porous hydrogel. Biosensors. 2020;10(10):130. doi:10.3390/bios10100130

176. Nelemans LC, Gurevich L. Drug delivery with polymeric nanocarriers-cellular uptake mechanisms. Materials (Basel). 2020;13:1-21. doi:10.3390/ma13020366

177. Dvornikov A, Malacrida L, Gratton E. The diver microscope for imaging in scattering media. Methods Protoc. 2019;2:1-12. doi: $10.3390 / \mathrm{mps} 2020053$

178. El-Hamadi M, Schätzlein AG. Nanoparticles in medical imaging. Fundam Pharm Nanosci. 2013;6:543-566.

179. Herranz F, Almarza E, Rodríguez I, et al. The application of nanoparticles in gene therapy and magnetic resonance imaging. Microsc. Res. Tech. 2011;74:577-591. doi:10.1002/jemt.20992

180. Sohal IS, O'Fallon KS, Gaines P, Demokritou P, Bello D. Ingested engineered nanomaterials: state of science in nanotoxicity testing and future research needs. Part Fibre Toxicol. 2018;15. doi:10.1186/s12989-018-0265-1

181. Kermanizadeh A, Pojana G, Gaiser BK, et al. In vitro assessment of engineered nanomaterials using a hepatocyte cell line: cytotoxicity, pro-inflammatory cytokines and functional markers. Nanotoxicology. 2013;7:301-313. doi:10.3109/17435390.2011.653416

182. Applications B, Pirzada M, Altintas Z. Nanomaterials for Healthcare. Sensors. 2019;19:5311-5367. doi:10.3390/s19235311

183. Holzinger M, Goff Le A, Cosnier S. Nanomaterials for biosensing applications: a review. Front Chem. 2014;2:1-10. doi:10.3389/ fchem.2014.00063

184. Shi J, Votruba AR, Farokhzad OC, et al. Nanotechnology in drug delivery and tissue engineering: from discovery to applications. Nano Lett. 2010;10:3223-3230. doi:10.1021/nl102184c

185. Mohammadi MR, Nojoomi A, Mozafari M, et al. Nanomaterials engineering for drug delivery: a hybridization approach. $J$ Mater Chem B. 2017;5:3995-4018. doi:10.1039/C6TB03247H

186. Lim M, Badruddoza AZM, Firdous J, et al. Engineered nanodelivery systems to improve dna vaccine technologies. Pharmaceutics. 2020;12:1-29. doi:10.3390/pharmaceutics 12010030

187. Chen J, Guo Z, Tian H, Chen X. Production and clinical development of nanoparticles for gene delivery. Mol Ther - Methods Clin Dev. 2016;3:16023. doi:10.1038/mtm.2016.23

188. Hasan A, Morshed M, Memic A, et al. Nanoparticles in tissue engineering: applications, challenges and prospects. Int J Nanomedicine. 2018:13:5637-5655. doi:10.2147/IJN.S153758

189. Fries CN, Curvino EJ, Chen J-L, et al. Advances in nanomaterial vaccine strategies to address infectious diseases impacting global health. Nat. Nanotechnol. 2020. doi:10.1038/s41565-020-0739-9

190. Semaeva E, Tenstad O, Skavland J, et al. Access to the spleen microenvironment through lymph shows local cytokine production, increased cell flux, and altered signaling of immune cells during lipopolysaccharide-induced acute inflammation. J. Immunol. 2010;184:4547-4556. doi:10.4049/jimmunol.0902049 
191. Doak SH, Liu Y, Chen C. Genotoxicity and Cancer. In: Adverse Effects of Engineered Nanomaterials: Exposure, Toxicology, and Impact on Human Health. 2nd ed. Elsevier Inc; 2017:423-445. doi:10.1016/B978-0-12-809199-9.00018-5

192. Kristensen BW, Noer H, Gramsbergen JB, Zimmer J, Noraberg J. Colchicine induces apoptosis in organotypic hippocampal slice cultures. Brain Res. 2003;964:264-278. doi:10.1016/S00068993(02)04080-5
193. Bhatia S, Bhatia S. Nanoparticles types, classification, characterization, fabrication methods and drug delivery applications. In: Natural Polymer Drug Delivery Systems. Springer International Publishing; 2016:33-93. doi:10.1007/978-3-319-41129-3 2

\section{Publish your work in this journal}

The International Journal of Nanomedicine is an international, peerreviewed journal focusing on the application of nanotechnology in diagnostics, therapeutics, and drug delivery systems throughout the biomedical field. This journal is indexed on PubMed Central, MedLine, CAS, SciSearch ${ }^{\mathbb{R}}$, Current Contents ${ }^{\mathbb{R}} /$ Clinical Medicine, $^{2}$
Journal Citation Reports/Science Edition, EMBase, Scopus and the Elsevier Bibliographic databases. The manuscript management system is completely online and includes a very quick and fair peer-review system, which is all easy to use. Visit http://www.dovepress.com/ testimonials.php to read real quotes from published authors. 